\title{
Intranasal Administration of Melanin-Concentrating Hormone Reduces Stress-Induced Anxiety- and Depressive-Like Behaviors in Rodents
}

\author{
Ju-Young $\mathrm{Oh}^{1,2,3}$, Quan Feng Liu ${ }^{4}$, Cai Hua ${ }^{5}$, Ha Jin Jeong ${ }^{5}$, Jae-Hwan Jang ${ }^{1,2,3}$, \\ Songhee Jeon ${ }^{5 *}$ and Hi-Joon Park ${ }^{1,2,3 *}$ \\ ${ }^{1}$ Department of Korean Medical Science, Graduate School of Korean Medicine, Kyung Hee University, Seoul 02447, \\ ${ }^{2}$ Studies of Translational Acupuncture Research (STAR), Acupuncture \& Meridian Science Research Center (AMSRC), \\ Kyung Hee University, Seoul 02447, ${ }^{3}$ BK21 PLUS Korean Medicine Science Center, College of Korean Medicine, \\ Kyung Hee University, Seoul 02447, ${ }^{4}$ Department of Neuropsychiatry, Graduate School of Oriental Medicine, \\ Dongguk University, Gwangju 38066, ${ }^{5}$ Department of Biomedical Sciences, \\ Center for Creative Biomedical Scientists at Chonnam National University, Gwangju 61469, Korea
}

Major depressive disorder is a complex neuropsychiatric disorder with few treatment options. Non-targeted antidepressants have low efficacy and can induce series of side effects. While a neuropeptide, melanin-concentrating hormone ( $\mathrm{MCH})$, is known to exhibit regulator of affective state, no study to date has assessed the anti-depressive effects of $\mathrm{MCH}$ in a stress-induced depression model. This study aimed to evaluate the pharmacological effects of intranasal administration of $\mathrm{MCH}$ on depression-related behavior in stressed rats and mice. Using a number of behavioral tests, we found that $\mathrm{MCH}$ treatment significantly decreased anxiety- and depressive-like behaviors induced by stress. Notably, the effects of $\mathrm{MCH}$ were equivalent to those of fluoxetine. MCH treatment also restored the activity of the mammalian target of rapamycin (mTOR) signaling pathway and normalized the levels of synaptic proteins, including postsynaptic density 95, glutamate receptor 1 , and synapsin 1 , which were all downregulated by stress. Interestingly, the protective effects of $\mathrm{MCH}$ were blocked by the mTOR inhibitor, rapamycin. These results suggest that $\mathrm{MCH}$ exhibits antidepressant properties by modulating the mTOR pathway. Altogether, this study provides an insight into the molecular mechanisms involved in the antidepressant-like effects of $\mathrm{MCH}$, thereby paving the way for the future clinical application of $\mathrm{MCH}$.

Key words: Depression, Mammalian target of rapamycin (mTOR), Melanin-concentrating hormone (MCH), Stress, Anxiety, Rapamycin

\section{INTRODUCTION}

Major depressive disorder (MDD) is a common but serious mood disorder that is diagnosed based on symptomatic criteria such as sadness or melancholia, irritability, feeling down, and a loss

Submitted June 26, 2020, Revised October 21,2020,

Accepted October 22, 2020

* To whom correspondence should be addressed. Hi-Joon Park, TEL: 82-2-961-9435, FAX: 82-2-961-0916 e-mail: acufind@khu.ac.kr

Songhee Jeon, TEL: 82-61-379-2862, FAX: 82-61-379-2753

e-mail: jsong0304@jnu.ac.kr of pleasure or interest in daily activities. It is often accompanied by other symptoms, including insomnia or hypersomnia, fatigue, and alterations in body weight, and is known to significantly increase the risk for suicide based on the Diagnostic and Statistical Manual of Mental Disorders (DSM-V) [1]. According to the World Health Organization [2], depression is the most common illness and the leading cause of disability worldwide. It has been estimated that 350 million people are affected by depression globally, with an increase of more than 18\% between 2005 and 2015.

Depression results from the complex interaction between social, psychological, and biological factors. Among them, disrupted function in one or more steps of synaptic transmission may be a crucial mechanism underlying depression [3-7]. Numerous stud-
Copyright (c) Experimental Neurobiology 2020. www.enjournal.org
This is an Open Access article distributed under the terms of the Creative Commons Attribution Non-Commercial License (http://creativecommons.org/licenses/by-nc/4.0) which permits unrestricted non-commercial use, distribution, and reproduction in any medium, provided the original work is properly cited. 
ies have shown that the serotonergic system is involved in the pathology of depression, and the majority of serotonergic neurons are located within the dorsal raphe nucleus (DRN). They play an important role in the regulation of emotional states and several other functions, including motor activity and sleep-wakefulness [6, 7]. It has been shown that low levels of serotonin and/or its metabolites are present in the urine and cerebrospinal fluid of patients with depression [3] as well as in suicidal patients with depressive disorders $[4,5]$. Among neuropeptides, melanin-concentrating hormone $(\mathrm{MCH})$ has been reported to be associated with MDD [8]. Furthermore, $\mathrm{MCH}$ is a known regulator of affective state and has been shown to interact with the serotonergic system [8]. It was first discovered in teleost fish [9] and was subsequently found in humans, rodents, and other mammals [10-12]. MCH-expressing (MCHergic) neurons project throughout the central nervous system, including the somatosensory cortex, isocortex, caudate putamen, hippocampus, nucleus accumbens, and amygdala [13, 14]. These neurons are primarily located in the lateral hypothalamus and adjacent zona incerta, projecting extensively throughout the brain [13]. MCH has two types of receptors: $\mathrm{MCH}$ receptor 1 (MCHR1) and 2 (MCHR2). Only MCHR1 is found in rodents [15], and is distributed throughout various brain regions including the cerebral cortex, basal ganglia, hypothalamus, and brainstem [16], while both MCHR1 and MCHR2 are found in humans [17]. Central MCH displays a wide range of functions, including the regulation of sleep [18, 19], olfactory function [20], and depression [8], and has a major role in energy maintenance by decreasing energy expenditure and stimulating feeding behavior [21]. However, these findings, mostly based on preclinical models, need to be validated in humans [22].

In the previous study, intranasally administered $\mathrm{MCH}$ ameliorated pain-related symptoms, including depressive-like behavior [23]. These results suggest that MCH may have anti-depressive effects, however, to date, no study has revealed the antidepressant effects of $\mathrm{MCH}$ in a stress-induced depression model. Therefore, the objective of the present study was to evaluate the antidepressantlike effects of intranasal administration of $\mathrm{MCH}$ on stress-induced depressive-like behaviors in rats and mice.

\section{MATERIALS AND METHODS}

\section{Animals}

Eight-week-old adult male Sprague Dawley rats (Samtako Animal Co., Seoul, Korea) weighing 200 220 g were used in behavioral tests. The rats were maintained on a 12/12-h light/dark cycle (lights on at 8:00 am, lights off at 8:00 pm) under a controlled temperature of $22 \pm 2^{\circ} \mathrm{C}$ and relative humidity of $55 \pm 15 \%$. All animals were acclimated to this condition for 7 days after arrival.

For all experiments using mice, 6-week-old healthy male ICR mice (Orient Bio., Seoul, Korea) were allowed 1 week for quarantine and acclimatization. The mice were housed on a 12/12-h light/dark cycle (lights on at 7:00 am, lights off at 7:00 pm) under a controlled temperature of $22 \pm 1^{\circ} \mathrm{C}$ and a relative humidity of $55 \pm 1 \%$. They were housed in polycarbonate cages and provided with tap water and commercial rodent chow (Samyang Feed, Daejeon, Korea) ad libitum.

The animal experiments in this study followed the 'Guide for Animal Experiments' provided by the Korean Academy of Medical Sciences, and the protocols were approved by the Institutional Animal Ethical Committee, Dongguk University, South Korea (Approval Number: IACUC-2016-034).

\section{Single prolonged stress in rats}

A single prolonged stress (SPS) model of post-traumatic stress disorder was used as an acute stress model. To examine the effects of different doses of $\mathrm{MCH}$ in the SPS model, the rats were divided into six groups ( $\mathrm{n}=6 /$ group): normal (Nor), SPS-induced stress (STR), STR+MCH $2 \mu \mathrm{g} / 30 \mu \mathrm{l}$, STR+MCH $8 \mu \mathrm{g} / 30 \mu \mathrm{l}$, STR+MCH $18 \mu \mathrm{g} / 30 \mu \mathrm{l}$, and STR+fluoxetine (Flu) as a positive control. To evaluate the mechanism(s) associated with the mTOR pathway, rapamycin, an inhibitor of mTOR, and four experimental groups were used (n=6/group): normal (Nor), SPS-induced stress (STR), $\mathrm{STR}+\mathrm{MCH} 18 \mu \mathrm{g} / 30 \mu \mathrm{l}(\mathrm{MCH})$, and STR+MCH+rapamycin $(\mathrm{MCH}+\mathrm{Rapa})$. For SPS, the limbs of rats were fixed with surgical tape on a metal board to restrict head motion. After immobilization for $2 \mathrm{~h}$, the rats were immediately forced to swim for $20 \mathrm{~min}$ in a plexiglass cylinder (50 $\mathrm{cm}$ in height, $24 \mathrm{~cm}$ in diameter), which was filled with $24^{\circ} \mathrm{C}$ fresh water to two-thirds of its volume. Then, the animals were dried, allowed to recover for $15 \mathrm{~min}$, and exposed to ether vapor until they became unconscious. After recovery from anesthesia, all animals were individually placed in a cage and left undisturbed for 7 days (Fig. 1A) [24]. The STR procedure was performed between 11 am and $4 \mathrm{pm}$.

\section{Immobility stress in mice}

To confirm the antidepressant-like effect of $\mathrm{MCH}$ in mice, mice were subjected to immobility-induced stress for 4 weeks. Stressed mice were treated with vehicle (STR), MCH (1, 5, or $25 \mu \mathrm{g} / 30 \mu \mathrm{l})$, or fluoxetine. In total, 36 male mice were blindly randomized into six different treatment groups ( $\mathrm{n}=6 /$ group): normal (Nor), immobility-stressed (STR), STR+MCH $1 \mu \mathrm{g} / 30 \mu \mathrm{l}$, STR+MCH $5 \mu \mathrm{g} / 30$ $\mu \mathrm{l}$, STR+MCH $25 \mu \mathrm{g} / 30 \mu \mathrm{l}$, and STR+fluoxetine (Flu) as a positive control. Animals in the stress group (STR) were individually placed into a flexible triangle-shaped vinyl screen with a nose-hole 
A

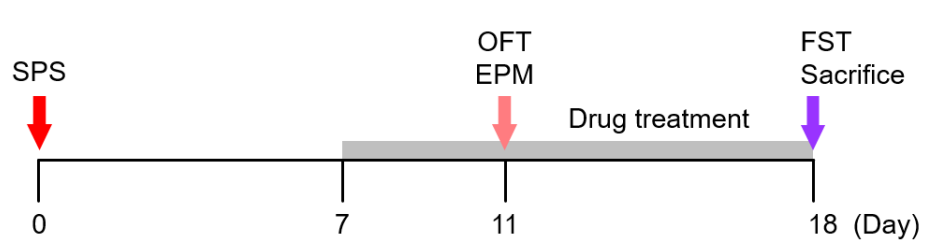

C - Nor $\rightarrow$ STR $\frac{2-8 \rightarrow 18}{\mathrm{MCH}(\mu \mathrm{g} / 30 \mu \mathrm{l})} \rightarrow \mathrm{Flu}$

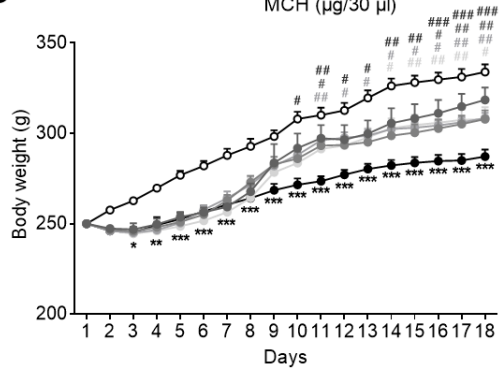

D

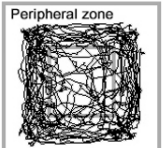

Nor

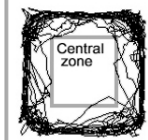

STR

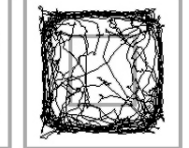

2

$\mathrm{MCH}(\mu \mathrm{g} / 30 \mu \mathrm{l})$
B

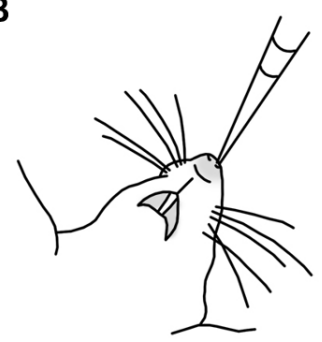

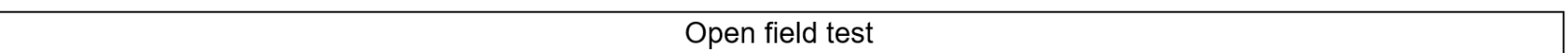

E

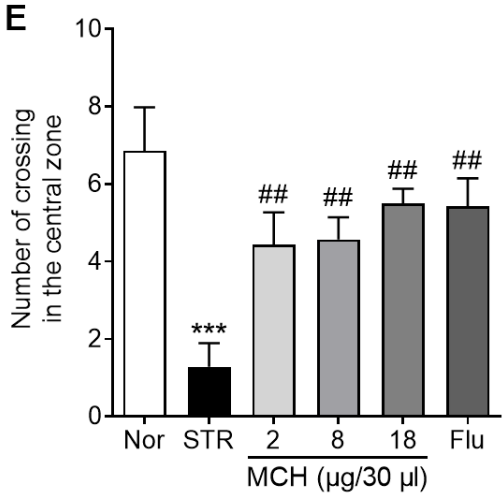

$\mathbf{F}$

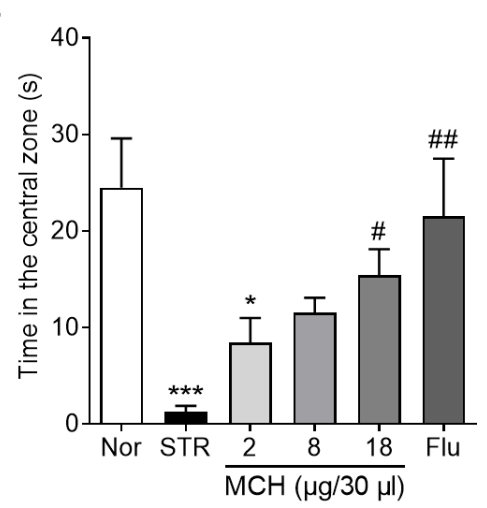

G

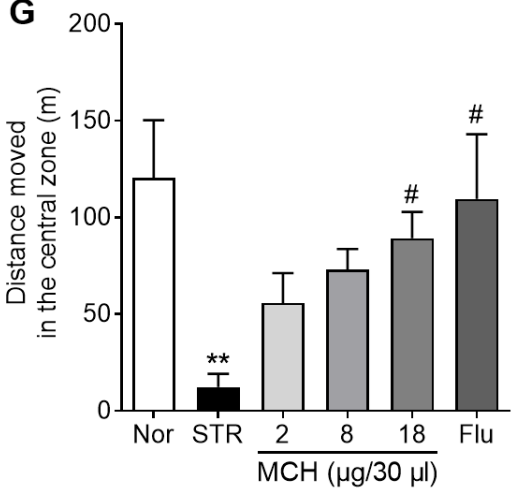

Elevated plus maze test
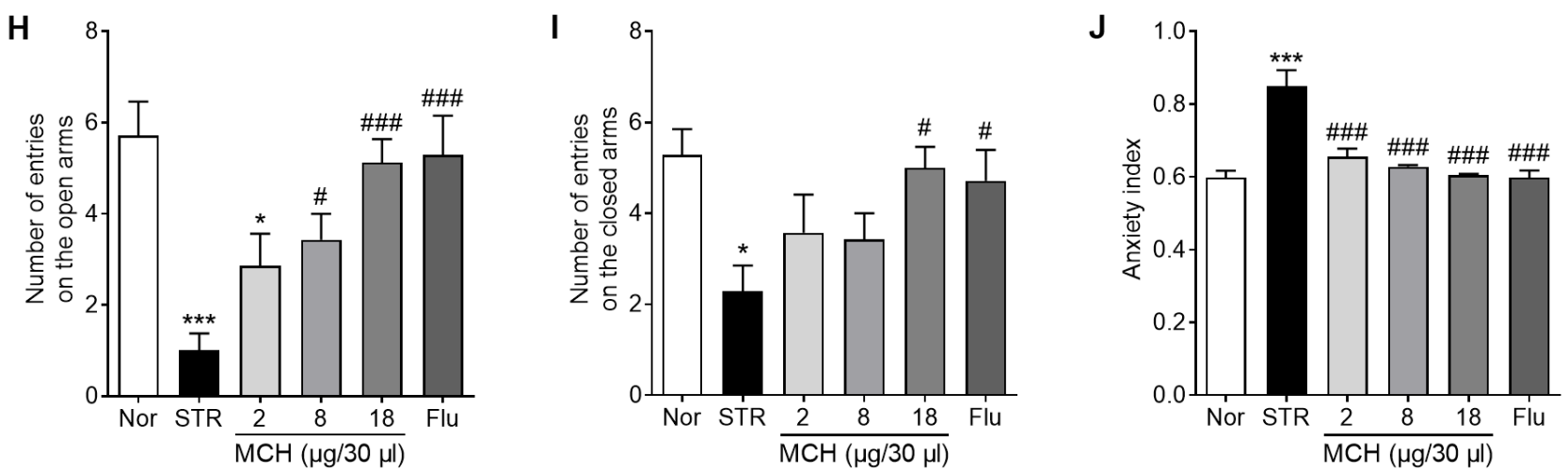

Fig. 1. Effects of MCH administration on depression- and anxiety-related behaviors in stressed rats. (A) Schematic representation of developing SPS and details of MCH administration. SPS was induced by immobilization ( $2 \mathrm{~h}$ ), forced swim $(20 \mathrm{~min})$, rest (15 $\mathrm{min})$, and ether anesthesia on day 1 . Rats were left undisturbed after SPS. OFT and EPM tests were performed on day 11. An FST was conducted and animals were sacrificed on day 18. (B) Intranasal MCH treatment in rats. (C) Variations in body weight of rats over the course of 18 days. MCH and fluoxetine significantly induced weight loss in rats from day 10 compared with STR. Effects of MCH on depression- and anxiety-related behaviors in (D G) OFT, (H J) EPM test, and (K M) FST in stressed rats. Data represent the means \pm SEM. $.{ }^{* * *} \mathrm{p}<0.001,{ }^{* *} \mathrm{p}<0.01,{ }^{\star} \mathrm{p}<0.05$ vs. Nor group $,{ }^{* * *} \mathrm{p}<0.001,{ }^{* *} \mathrm{p}<0.01,{ }^{*} \mathrm{p}<0.05$ vs. STR group. SPS, single prolonged stress; OFT, open field test; EPM, elevated plus maze; FST, Forced swimming test; Nor, normal; STR, stress; Flu, fluoxetine. 


\section{Forced swimming test}
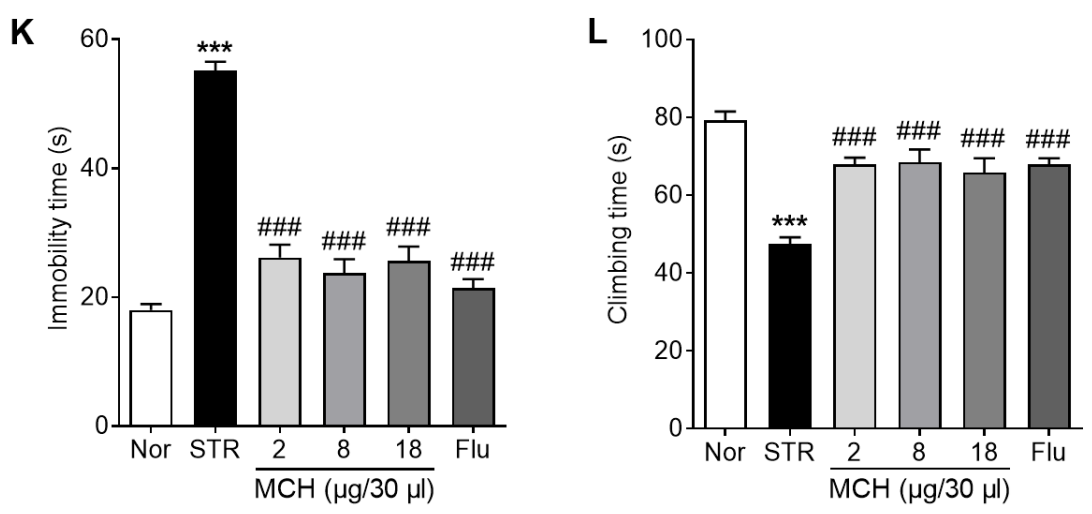

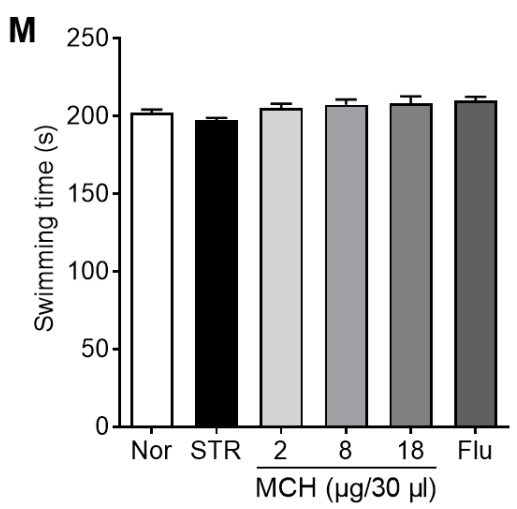

Fig. 1. Continued.

for ventilation and exposed to immobility stress for $4 \mathrm{~h}$ a day over 4 weeks. This model was used to assess the psychological consequences of chronic stress, weighed and compared between groups to investigate the nutritional status. In addition, to examine the effect of antidepressant-like effects of $\mathrm{MCH}$ in mice, we measured the energy homeostasis of each experimental group by calculating food efficiency ratio (FER) from food intake and total weight gain. At the end of the experimental period, all animals were decapitated, and the prefrontal cortices (PFC) were immediately collected and frozen at $-80^{\circ} \mathrm{C}$ until further analysis. Blood samples were also collected from the heart via cardiac puncture prior to brain excision.

\section{Pharmacological treatments}

In the acute stress experiment in rats, $\mathrm{MCH}(2,8$, or $18 \mu \mathrm{g}$ dissolved in $30 \mu \mathrm{l}$ of saline; Tocris Biosciences, Bristol, UK; 3806) was administered intranasally to the rats for 12 consecutive days (Fig. 1A, B). Saline was used as a negative control. As a positive control, fluoxetine (10 mg/kg, Sigma-Aldrich, St. Louis, MO, USA) was dissolved in a sterile saline solution and applied intraperitoneally (i.p.). Fluoxetine was administered $2 \mathrm{~h}$ before behavioral tests to maintain fluoxetine effects in the central nervous system. Both $\mathrm{MCH}$ and fluoxetine were administered 7 days after exposure to stress. The mTOR inhibitor rapamycin (Rapa, $110 \mu \mathrm{g} / 30 \mu \mathrm{l}$, Cayman, Ann Arbor, MI, USA) was applied intranasally 30 min after administering $\mathrm{MCH}$.

In the chronic immobility stress experiment in mice, $\mathrm{MCH}$ at 1,5, or $25 \mu \mathrm{g}$ in $30 \mu \mathrm{l}$ was dropped into the nostrils under stress conditions for 4 weeks. As a positive control, fluoxetine hydrochloride was orally administered at $10 \mathrm{mg} / \mathrm{ml}$ for 4 weeks.

$\mathrm{TC}-\mathrm{MCH} 7 \mathrm{c}$, an $\mathrm{MCH}$ receptor type 1 antagonist $(10 \mathrm{mg} / \mathrm{kg}$; catalog 4365, Tocris Bioscience), was dissolved in $80 \mu$ of dimethyl sulfoxide. It was then diluted to a total volume of $8 \mathrm{ml}$ with saline and administered intraperitoneally $30 \mathrm{~min}$ before each $\mathrm{MCH}$ treatment.

\section{Behavior tests}

\section{Open field test (OFT)}

The potential effects of $\mathrm{MCH}$ on anxiety-related behaviors were assessed in the OFT in rats on day 11 (Fig. 1A). The test was conducted in a box contained in a dark room with dimensions of $60 \times 60 \times 30 \mathrm{~cm}$. The box was divided into 16 identical squares ("zones"). In each test, one rat was placed into the center of the arena and the frequency of crossing the center zone as well as the total distance traveled was recorded for $5 \mathrm{~min}$. After each rat was tested, the box was thoroughly cleaned with $70 \%$ alcohol. The experimenter was blinded to the group information. The total distance traveled and the time spent in the zone during the test were analyzed automatically using an S-MART program (Pan Lab Co., Barcelona, Spain).

\section{Elevated plus maze (EPM) test}

The EPM test was performed on day 11, immediately following OFT, to analyze anxiety-related behaviors in rats (Fig. 1A). The plus maze consisted of four arms $(50 \times 10 \mathrm{~cm}$ each $)$ placed in a plus (+) shape, raised $50 \mathrm{~cm}$ above the floor. Two opposite arms were enclosed by $20 \mathrm{~cm}$ walls (closed arms), and the other two arms were not enclosed (open arms). Movements on the platforms were video-recorded for $5 \mathrm{~min}$ using the S-MART program located on the ceiling above the center of the maze. Arm entry was defined as entering an arm with all four paws. The following three measurements were taken: the number of open arm entries, the number of closed arm entries, and the percentage of open arm time.

Anxiety reduction, manifested by open arm exploration in the 
EPM test, was defined as an increase in the number of entries into open arms compared with the total entries into either open or closed arms, or an increase in the fraction of time spent in open arms compared with total time spent on either arm. Total arm entries were used to monitor changes in the locomotor activity of rats.

To compare the overall effect on anxiety behavior, we defined anxiety index by incorporating the assessed values. The index was calculated as follows:

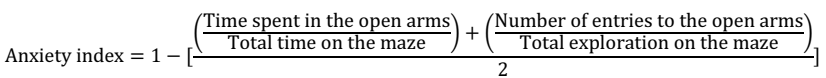

Anxiety index values range from 0 to 1 , with an increase in the index indicating increased anxiety-like behavior [25].

\section{Forced swimming test (FST)}

To evaluate depression severity, a modified FST was performed as previously described [26]. Rats were considered immobile when they remained in the water without struggling, but only made the necessary movements to keep their head above the water. Immobility behavior was represented as the time interval in which rats did not show any escape response. Climbing behavior was defined as an upward-directed movement of the forepaws along the side of the swim chamber.

In the case of mice, each mouse was placed in a plexiglass cylinder (25 cm in height, $15 \mathrm{~cm}$ in internal diameter) containing water at a temperature of $25 \pm 1^{\circ} \mathrm{C}$ with a depth of $10 \mathrm{~cm}$, which prevented mice from escaping the cylinder or touching the bottom. The 5-min swim test was recorded for behavioral analysis of immobility, climbing, and swimming.

\section{Tail suspension test (TST)}

Mice were suspended individually by their tails $40 \mathrm{~cm}$ above the floor with adhesive tape placed approximately $1 \mathrm{~cm}$ proximal from the tip of their tails, while isolated both acoustically and visually. After a few minutes of vigorous activity, the mice became passive and motionless. The total immobility period was scored throughout a 6-min test. Mice were considered immobile when there was no limb or body movement, except for those caused by respiration. A decrease in the duration of immobility indicated an antidepressant-like effect.

\section{Corticosterone levels}

Serum was isolated by centrifugation at 3,000 rpm for $15 \mathrm{~min}$ at $4^{\circ} \mathrm{C}$ immediately after trunk blood collection and kept at $-80^{\circ} \mathrm{C}$. Serum corticosterone levels were measured in duplicate using an enzyme-linked immunoassay (ELISA, Enzo Life, USA) according to the manufacturer's instructions.

\section{Western blotting}

Brain samples were homogenized in $200 \mu \mathrm{l}$ of lysis buffer (CyQUANT; Invitrogen, Eugene, OR, USA) supplemented with phosphatase inhibitor cocktail and protease inhibitor cocktail tablets (Thermo Scientific, Waltham, MA, USA). The samples were centrifuged at $12,000 \mathrm{rpm}$ for $15 \mathrm{~min}$ at $4^{\circ} \mathrm{C}$, and the supernatants were collected. Protein levels were determined using a bicinchoninic acid assay (Thermo Scientific). Equal amounts of protein $(10 \mu \mathrm{g})$ were separated by $10 \%$ sodium dodecyl sulfate-polyacrylamide gel electrophoresis and transferred to a polyvinylidene difluoride membrane (Millipore, Billerica, MA, USA). For immunodetection, the blots were blocked with 5\% skim milk in Tris-buffered saline containing $0.1 \%$ Tween-20 (TBS-T) for $1 \mathrm{~h}$ at room temperature and incubated overnight at $4^{\circ} \mathrm{C}$ with primary antibodies. The following primary antibodies were used: p-Akt (1:1,000,\#4058), total Akt (1:1,000, \#4691), p-ERK1/2 (1:3,000,\#4370), total ERK1/2 (1:3,000, \#9102), p-mTOR (1:500, \#2971), total mTOR (1:500, \#2983), p-p70S6K (1:500,\#9204), p-PSD95 (1:1,000,\#45737), total PSD95 (1:1,000, \#3409), p-GluR1 (1:1,000,\#8084), total GluR1 (1:500,\#13185), p-Synapsin 1 (p-Syn 1, 1:1,000,\#88246), and total Syn 1 (1:1,000, \#9297) from Cell Signaling Technology (Danvers, MA, USA) and $\beta$-actin (1:30,000, \#A1978) from Sigma-Aldrich. After washing with TBS-T three times (10 min per wash) at room temperature, the membrane was incubated with secondary horseradish peroxidase-conjugated goat anti-rabbit (Pierce, Rockford, IL, USA) or anti-mouse (Thermo Scientific; 31430) antibodies. The signal was visualized using a chemiluminescence kit (Super Signal West Pico; Pierce). Signal intensity was analyzed using ImageJ software (National Institutes of Health, Bethesda, MD, USA).

\section{Distribution of FITC-labeled MCH after intranasal admin- istration}

Thirty minutes after the intranasal administration of either MCH-FITC $(10 \mu \mathrm{g} / 30 \mu \mathrm{l}$, GL Biochem; Shanghai, China) or saline $(30 \mu \mathrm{l})$, the slightly anesthetized mice were transcardially perfused with PBS followed by ice-cold 10\% formalin. The brains were immediately removed and stored at $-80^{\circ} \mathrm{C}$ for $1 \mathrm{~h}$. Next, coronal sections (40- $\mu \mathrm{m}$ thick) of the brain were cut to encompass the entire brain. Coverslips were mounted using a mounting medium containing DAPI (H-1200, Vector Laboratories Inc., Burlingame, CA, USA), and all images were collected using an Olympus FV1000 laser confocal scanning microscope (Olympus Corporation, Shinjuku, Tokyo, Japan). 


\section{Intracerebroventricular injection of $\mathrm{MCH}$}

The mice were anesthetized with an i.p. injection of a mixture of Zoletil:Rompun (3:1) and fixed in a stereotaxic frame (Stoelting, Wood Dale, IL, USA). An injection cannula (CMA/7; CMA Microdialysis, Sweden) was inserted into the DRN at coordinates 4.5 $\mathrm{mm}$ posterior to bregma, $1.5 \mathrm{~mm}$ lateral to the midline, $2.8 \mathrm{~mm}$ ventral to the dura, and at a $30^{\circ}$ angle from the vertical plane to avoid the sagittal sinus. The guide cannula and three small stainless steel screws serving as anchors were cemented to the skull with dental cement. MCH $(0.2 \mu \mathrm{l})$ was infused over a period of $5 \mathrm{~min}$ at a constant flow using a microinjection pump (KDS 310 plus Nano Legacy syringe pump, Kd Scientific, Holliston, MA, USA), and the injector was left in place for 5 min after injection to allow diffusion. After surgery, the mice were singly housed.

\section{Statistical analysis}

GraphPad Prism 8 software (GraphPad Software Inc., San Diego, CA, USA) was used for all statistical analyses. Data are expressed as the mean \pm standard error of the mean (SEM). Group comparisons were performed by one-way analysis of variance (ANOVA) followed by the Newman-Keuls post hoc test. Analyses for body weight were performed using a two-way ANOVA with repeated measures and the Bonferroni post hoc test for pairwise multiple comparisons. In all analyses, differences were considered statistically significant at $\mathrm{p}<0.05$.

\section{RESULTS}

\section{Effect of MCH on the body weight of stressed rats}

Stress efficacy was monitored by measuring body weight. The rats were weighed over the course of STR induction and $\mathrm{MCH}$ intranasal administration for 18 days (Fig. 1A, B). Two-way ANOVA showed a significant difference among the groups in weight change $\left[\mathrm{F}_{5,648}=105.3, \mathrm{p}<0.0001\right]$ and in the timing of the effect (days) $\left[\mathrm{F}_{17}\right.$, $\left.{ }_{648}=184.5, \mathrm{p}<0.0001\right]$. Post hoc tests revealed that the STR group showed a significant decrease in body weight compared with the normal (Nor) group from day 3 of STR induction $(\mathrm{p}<0.05)$. However, after day 10 of STR induction, rats in the MCH $18 \mu \mathrm{g} / 30 \mu \mathrm{l}$ group gained a significant amount of body weight compared with the STR group ( $\mathrm{p}<0.05$, Fig. $1 \mathrm{C})$.

\section{Effect of MCH on the anxiogenic behavior of stressed rats}

OFT was performed to measure changes in anxiety and exploratory behavior after treatment with $\mathrm{MCH}$. Rats were exposed to a novel environment in an open field apparatus, and their activities were analyzed. A one-way ANOVA of the OFT data revealed a significant effect of $\mathrm{MCH}$ on anxiety behavior in the numbers of crossings in the central zone $\left[\mathrm{F}_{5,42}=6.469, \mathrm{p}=0.0002\right]$, time in the central zone $\left[\mathrm{F}_{5,42}=5.572, \mathrm{p}=0.0006\right]$, and distance moved in the central zone $\left[\mathrm{F}_{5,42}=3.586, \mathrm{p}=0.0096\right]$. Post hoc analyses revealed that the total number of line crossings in the center zone was significantly reduced in the STR group (vs. Nor, $\mathrm{p}<0.001$, Fig. 1D G). However, this decrease was restored in the $\mathrm{MCH}$ group $(\mathrm{p}<0.01$, Fig. 1D G), indicating an improvement in anxiety-related behavior.

To further investigate the effects of $\mathrm{MCH}$ on anxiety behaviors, rats were assessed during open arm exploration in the EPM test. A one-way ANOVA revealed significant group effects in the number of entries into the open arms $\left[\mathrm{F}_{5,42}=7.815, \mathrm{p}<0.0001\right]$ and closed arms $\left[\mathrm{F}_{5,42}=3.425, \mathrm{p}=0.0121\right]$. Post hoc comparisons showed that the STR group displayed a decrease in the number of entries into the open arms $(\mathrm{p}<0.001)$ and closed arms $(\mathrm{p}<0.05)$ compared with the Nor group (Fig. 1H I). A significant restoration in the number of entries into the open arms was observed in the $\mathrm{MCH}(18 \mu \mathrm{g} / 30$ $\mu \mathrm{l})$ group compared with that in the STR group $(\mathrm{p}<0.001)$. Overall, the anxiety index revealed a significant group effect $\left[\mathrm{F}_{5,42}=17.95\right.$, $\mathrm{p}<0.0001]$. The anxiety index calculated based on the number of visits and the time spent in the open and closed arms was lower in the MCH group than in the STR group ( $\mathrm{p}<0.001$, Fig. 1J).

\section{Effect of MCH on depressive-like behavior of stressed rats}

To determine the effects of MCH on depressive-like behaviors, rats were exposed to FST. A one-way ANOVA of performance data in FST indicated significant group effects on immobility $\left[\mathrm{F}_{5}\right.$, $\left.{ }_{37}=49.64, \mathrm{p}<0.0001\right]$ and climbing time $\left[\mathrm{F}_{5,37}=17.64, \mathrm{p}<0.0001\right]$ but not swimming time $\left[\mathrm{F}_{5,37}=2.480, \mathrm{p}=0.0524\right]$. Post hoc analyses revealed a significant increase in depressive phenotype (duration of immobility) in the STR group compared with that in the Nor group $(\mathrm{p}<0.001$, Fig. $1 \mathrm{~K})$. In contrast, the $\mathrm{MCH}$ group exhibited a marked $(p<0.001)$ decrease in the duration of immobility compared with the STR group, indicating that $\mathrm{MCH}$ alleviated depressive-like behaviors. Similarly, an analysis of climbing time, another key indicator of depressive-like behavior, revealed a significant decrease in the STR group (vs. Nor, $\mathrm{p}<0.001$ ), which was restored by treatment with MCH (vs. STR, p<0.001, Fig. 1L). The stressed groups displayed only slight variations in swimming time, suggesting that the results observed in this study were caused by increased depressive-like behavior and not by motor function deficits (Fig. $1 \mathrm{M})$.

\section{Effects of MCH on the MTOR signaling pathway in the PFC following stress}

The mTOR pathway in the PFC is demonstrated to be closely involved in depression $[27,28]$. To investigate whether the anxio- 
A
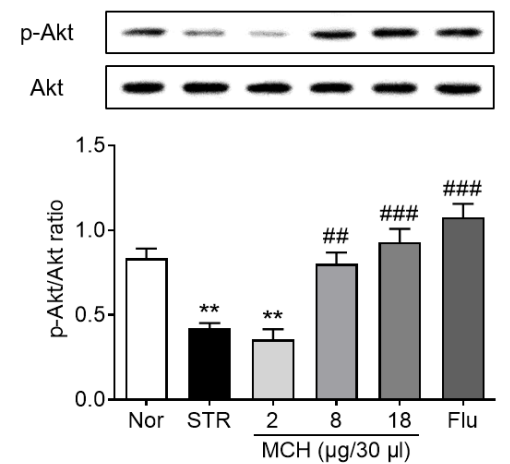

D
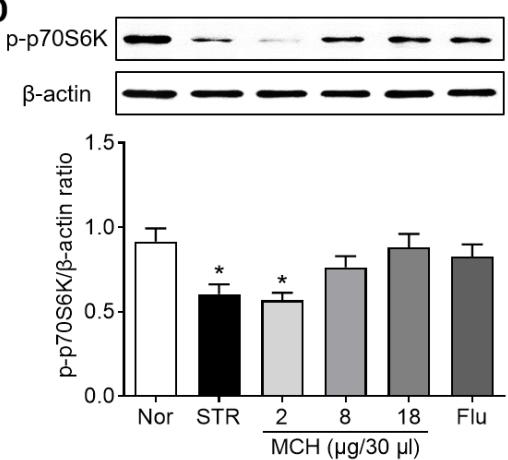

B
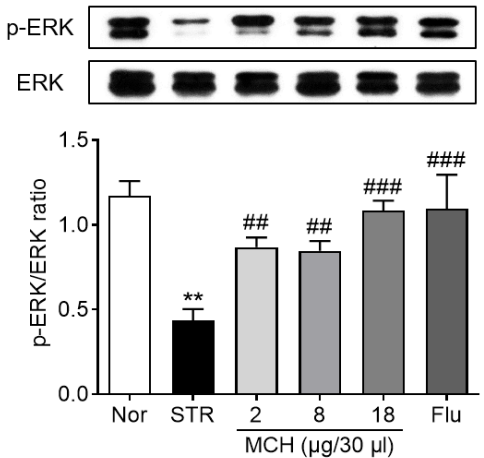

C
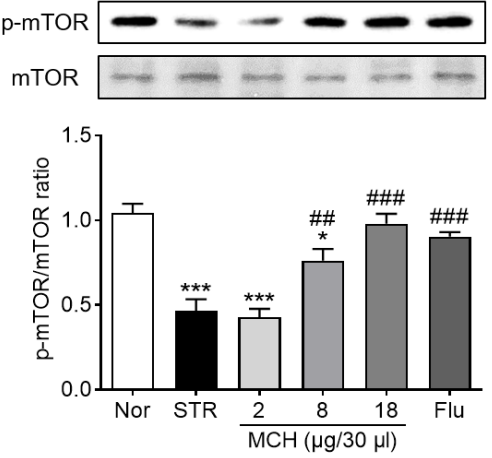

E
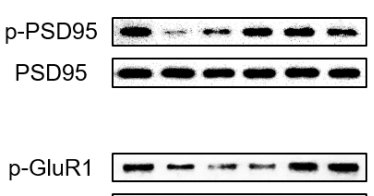

GluR1

p-Syn1

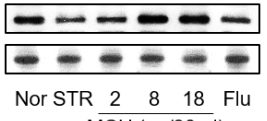
$\mathrm{MCH}(\mu \mathrm{g} / 30 \mu \mathrm{l})$

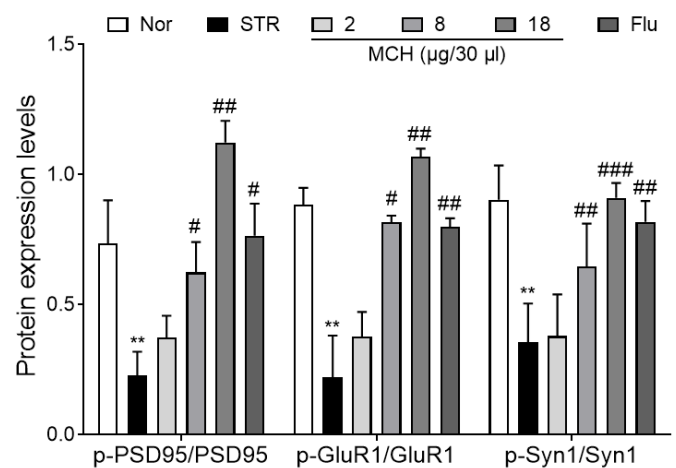

Fig. 2. Activation of the mTOR signaling pathway and synaptic proteins after MCH administration. Western blot analysis of protein expression levels of (A) Akt, (B) ERK, (C) mTOR, (D) p70S6K, and (E) synaptic proteins in stressed rats. The amount of phosphorylated proteins was normalized to that of total proteins and presented in bar graphs except p70S6K. The amount of phosphorylated p70S6K was normalized to that of $\beta$-actin. Data represent the means \pm SEM. ${ }^{* * *} \mathrm{p}<0.001,{ }^{* *} \mathrm{p}<0.01,{ }^{*} \mathrm{p}<0.05$ vs. Nor group, ${ }^{\# * *} \mathrm{p}<0.001,{ }^{\# *} \mathrm{p}<0.01,{ }^{*} \mathrm{p}<0.05$ vs. STR group. Nor, normal; STR, stress; Flu, fluoxetine.

lytic and antidepressant-like effects of MCH are associated with the mTOR signaling pathway, the expression of major proteins in the mTOR signaling pathway were analyzed after MCH administration in stressed rats. Statistical analyses showed significant phosphorylation levels of several proteins in the PFC: p-Akt/Akt $\left[\mathrm{F}_{5,17}=19.36, \mathrm{p}<0.0001\right], \mathrm{p}-$ ERK/ERK $\left[\mathrm{F}_{5,17}=11.67, \mathrm{p}=0.0003\right]$, $\mathrm{p}-$ $\mathrm{mTOR} / \mathrm{mTOR}\left[\mathrm{F}_{5,17}=21.40, \mathrm{p}<0.0001\right]$, and $\mathrm{p}$-p $70 \mathrm{~S} 6 \mathrm{~K} / \beta$-actin $\left[\mathrm{F}_{5}\right.$, $\left.{ }_{17}=4.526, \mathrm{p}=0.0150\right]$.

Post hoc analyses revealed that the levels of $\mathrm{p}-\mathrm{Akt}(\mathrm{p}<0.01$, Fig. $2 \mathrm{~A})$, p-ERK (p $<0.01$, Fig. $2 \mathrm{~B}), \mathrm{p}-\mathrm{mTOR}(\mathrm{p}<0.001$, Fig. $2 \mathrm{C})$, and p-p70S6K ( $<<0.05$, Fig. 2D) in the STR group were significantly lower than those in the Nor group. However, the expression levels of p-Akt (p $<0.01$, Fig. $2 A$ ), p-ERK (p $<0.01$, Fig. $2 B$ ), and p-mTOR $(p<0.01$, Fig. 2 C) were restored following the administration of $\mathrm{MCH}(8 \mu \mathrm{g} / 30 \mu \mathrm{l})$. Moreover, the levels of $\mathrm{p}$-Akt ( $<0.001$, Fig. $2 \mathrm{~A}$ ), p-ERK (p<0.001, Fig. $2 \mathrm{~B})$, and p-mTOR ( $<0.001$, Fig. $2 \mathrm{C})$ were significantly increased in the $\mathrm{MCH}(18 \mu \mathrm{g} / 30 \mu \mathrm{l})$ group compared with those in the STR group.

\section{Effects of MCH on synaptic proteins in the PFC following} stress

Synaptic plasticity has been shown to be involved in the pathogenesis of depression. Therefore, we examined the phosphorylation of major synaptic proteins, including postsynaptic density 95 (PSD95), glutamate receptor 1 (GluR1), and synapsin 1 (Syn1), which are known to be associated with antidepressant-like effects and synaptic plasticity.

Statistical analyses indicated a significant effect of $\mathrm{MCH}$ on p-PSD95/PSD95 $\left[\mathrm{F}_{5,17}=20.70, \mathrm{p}<0.0001\right]$, $\mathrm{p}-\mathrm{GluR} 1 / \mathrm{GluR} 1\left[\mathrm{~F}_{5}\right.$ $\left.{ }_{17}=10.06, p=0.0006\right]$, and $p-S y n 1 / \operatorname{Syn} 1\left[F_{5,17}=9.136, p=0.0009\right]$ in the PFC. A post hoc test revealed that $\mathrm{p}-\mathrm{PSD} 95$ ( $\mathrm{p}<0.01)$, $\mathrm{p}$-GluR1 $(\mathrm{p}<0.01)$, and $\mathrm{p}-\mathrm{Syn} 1(\mathrm{p}<0.01)$ were downregulated in the STR group compared with the Nor group (Fig. 2E). However, the levels of p-PSD95 ( $<<0.01)$, p-GluR1 $(\mathrm{p}<0.01)$, and p-Syn1 $(\mathrm{p}<0.001)$ were restored in the $\mathrm{MCH}(8,18 \mu \mathrm{g} / 30 \mu \mathrm{l})$ group (Fig. 2E).

\section{Pretreatment with the mTOR inhibitor rapamycin blocked the effect of MCH}

To confirm the involvement of the mTOR signaling pathway in the effects of $\mathrm{MCH}$, we intranasally injected rapamycin, an inhibi- 

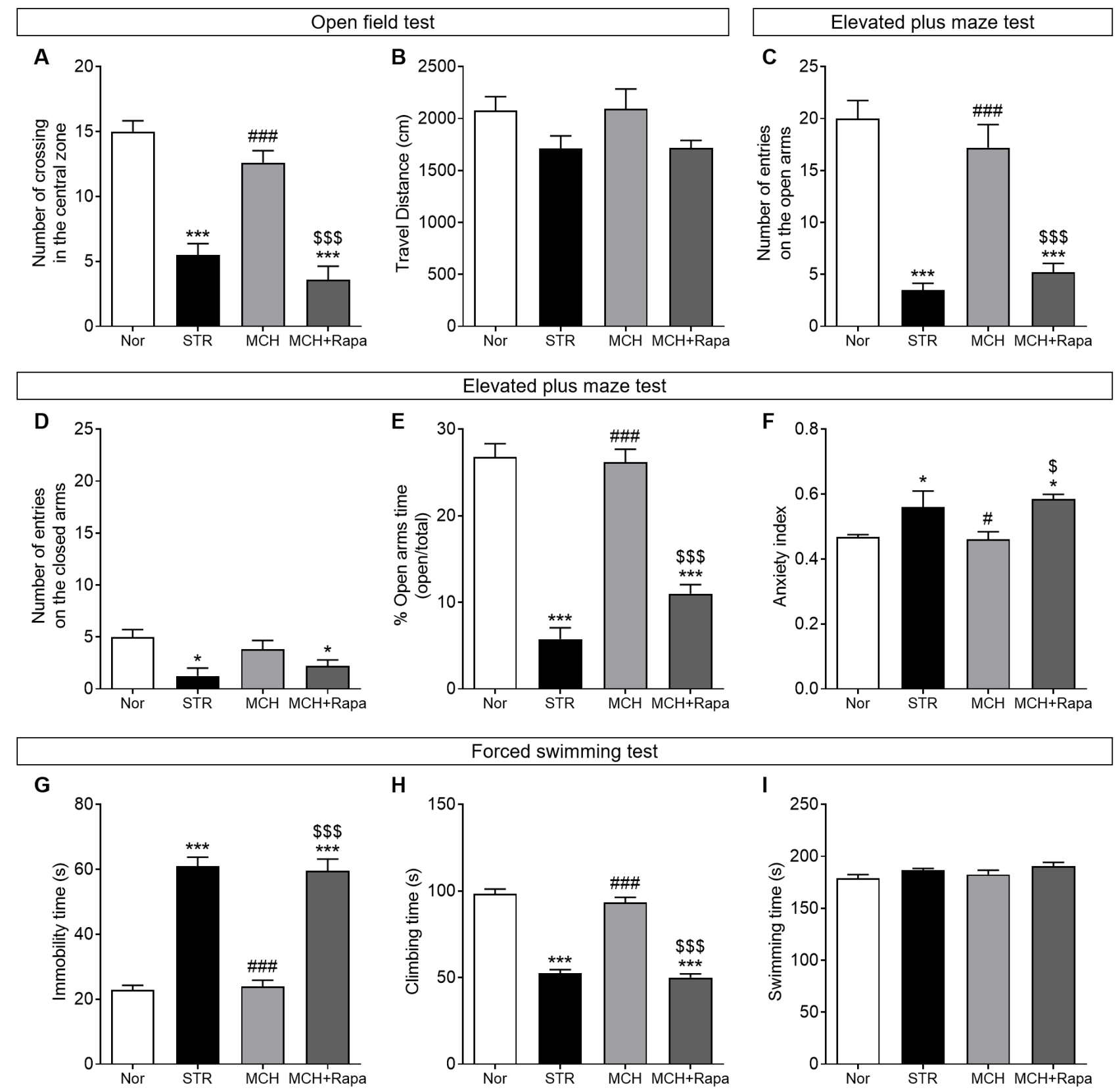

Fig. 3. Rapamycin blocks the antidepressant-like and anxiolytic-like effects of $\mathrm{MCH}$. Effects of $\mathrm{MCH}(18 \mu \mathrm{g} / 30 \mu \mathrm{l})$ administration on depression and anxiety behaviors in (A, B) OFT, (C F) EPM test, and (G I) FST in stressed rats. Pretreatment with the mTOR inhibitor rapamycin $(110 \mu \mathrm{g} / 30 \mu \mathrm{l}$, intranasal) blocked the antidepressant and anxiolytic effects of $\mathrm{MCH}$. Data represent the means \pm SEM. ${ }^{* * *} \mathrm{p}<0.001,{ }^{*} \mathrm{p}<0.05$ vs. Nor group, ${ }^{* \# *} \mathrm{p}<0.001$ vs. STR group, ${ }^{\$ \$ \$} \mathrm{p}<0.001,{ }^{\$} \mathrm{p}<0.05$ vs. MCH group. Nor, normal; STR, stress; Rapa, rapamycin; OFT, open field test; EPM, elevated plus maze; FST, forced swim test.

tor of the mTOR pathway, at a dose of $110 \mu \mathrm{g} / 30 \mu \mathrm{l}$ and then performed behavioral tests.

First, the rats were subjected to OFT. A one-way ANOVA of the OFT data indicated that the anxiolytic effect of $\mathrm{MCH}$ was significantly blocked in the $\mathrm{MCH}+$ Rapa group $\left[\mathrm{F}_{3,18}=35.59, \mathrm{p}<0.0001\right]$. Post hoc analyses showed that the MCH+Rapa group exhibited a substantially decreased number of lines crossing the central zone compared with the MCH group ( $<<0.001$, Fig. 3 A). However, the travel distance did not differ among groups $\left[\mathrm{F}_{3,18}=2.397\right.$, $\mathrm{p}=0.1088$ ], indicating that their motor function was not affected (Fig. 3B).

A one-way ANOVA of the EPM test data revealed significant ef- 
fects of rapamycin treatment on the number of entries into open $\left[\mathrm{F}_{3,18}=27.30, \mathrm{p}<0.0001\right]$ and closed arms $\left[\mathrm{F}_{3,18}=4.977, \mathrm{p}=0.0136\right]$ of the maze. According to post hoc analyses, the $\mathrm{MCH}+\mathrm{Rapa}$ group showed fewer entries into the open arms ( $<<0.001$, Fig. 3C), but not into the closed arms, compared with the MCH group (Fig. 3D), supporting that rapamycin suppressed the anxiolytic effects of $\mathrm{MCH}$. Statistical analyses of EPM data showed that the percentage of time in open arms $\left[\mathrm{F}_{3,18}=58.38, \mathrm{p}<0.0001\right]$ differed significantly among the four groups. Post hoc analyses revealed that rats in the STR group spent significantly less time in the open arms of the maze compared with the Nor group $(\mathrm{p}<0.001)$, which was restored by $\mathrm{MCH}$ treatment $(\mathrm{p}<0.001$, Fig. 3E). However, this improvement was abolished in the $\mathrm{MCH}+\mathrm{Rapa}$ group, with significantly less time spent in the open arms compared with that in the $\mathrm{MCH}$ group ( $<<0.001$, Fig. $3 \mathrm{E})$. Overall, the anxiety index revealed a significant group effect $\left[\mathrm{F}_{3,18}=55.70, \mathrm{p}=0.0049\right]$. The anxiety index calculated based on the number of visits to and time spent in the open and closed arms was lower in the $\mathrm{MCH}$ group than in the $\mathrm{MCH}+$ Rapa group ( $\mathrm{p}<0.05$, Fig. $3 \mathrm{~F}$ ).

Lastly, the FST was conducted to test the role of the mTOR signaling pathway in the antidepressant-like effects of $\mathrm{MCH}$. A one-way ANOVA of the FST data showed that immobility time $\left[\mathrm{F}_{3,18}=69.59, \mathrm{p}<0.0001\right]$ was significantly increased, and climbing time $\left[\mathrm{F}_{3,18}=102.0, \mathrm{p}<0.0001\right]$ was significantly decreased in the $\mathrm{MCH}+\mathrm{Rapa}$ group, and that swimming time was not different between groups $\left[\mathrm{F}_{3,18}=1.996, \mathrm{p}=0.1579\right]$. Post hoc analyses showed that the $\mathrm{MCH}+\mathrm{Rapa}$ group exhibited a pronounced depressionlike phenotype (increased immobility) compared with the $\mathrm{MCH}$ group ( $\mathrm{p}<0.001$, Fig. $3 \mathrm{G}$ ). In addition, the $\mathrm{MCH}+\mathrm{Rapa}$ group exhibited a decrease in climbing time compared with the $\mathrm{MCH}$ group ( $<<0.001$, Fig. $3 \mathrm{H}$ ). However, the groups showed no significant difference in swimming time (Fig. 3I). Taken together, our findings from the behavioral tests suggest that pretreatment with the mTOR inhibitor rapamycin suppresses the effects of $\mathrm{MCH}$ on anxiety and depressive-like behaviors.

\section{Effects of MCH on depressive-like behavior in immobility- induced mice}

To confirm the antidepressant-like effects of $\mathrm{MCH}$ in mice, we examined the energy homeostasis of each experimental group by calculating FER from food intake and total weight gain (Fig. 4A D). A one-way ANOVA revealed differences in total weight gain $\left[\mathrm{F}_{5,23}=24.09, \mathrm{p}<0.0001\right]$, total food intake $\left[\mathrm{F}_{5,23}=5.440\right.$, $\mathrm{p}=0.0032]$, and total FER $\left[\mathrm{F}_{5,18}=1.079, \mathrm{p}=0.405\right]$. Compared with the STR group, the Nor group showed increased food intake and weight gain. However, there was no significant difference in food intake or weight gain between the MCH and STR groups, sug- gesting that administration of MCH did not affect body energy metabolism.

Next, we examined the effect of MCH on depression-like behavior using the TST $\left[\mathrm{F}_{5,23}=8.549, \mathrm{p}=0.0003\right]$. The STR group showed increased immobility time compared with the Nor group $(\mathrm{p}<0.01)$, whereas $\mathrm{MCH}(1$ or $5 \mu \mathrm{g} / 30 \mu \mathrm{l})$ and fluoxetine eliminated the stress-induced increase (MCH $1 \mu$ g or fluoxetine, $\mathrm{p}<0.001 ; \mathrm{MCH}$ $5 \mu \mathrm{g}, \mathrm{p}<0.01$; Fig. 4E). We then assessed the effect of $\mathrm{MCH}$ in the FST. A one-way ANOVA revealed differences in immobility $\left[\mathrm{F}_{5}\right.$, $\left.{ }_{23}=4.523, \mathrm{p}=0.0076\right]$, climbing $\left[\mathrm{F}_{5,23}=15.67, \mathrm{p}<0.0001\right]$, and swimming time $\left[\mathrm{F}_{5,23}=3.529, \mathrm{p}=0.0213\right]$. Post hoc analyses showed no significant difference in immobility and climbing time between the Nor and STR groups, while the MCH $(1 \mu \mathrm{g} / 30 \mu \mathrm{l})$ group exhibited a marked difference (immobility, $\mathrm{p}<0.05$; climbing, $\mathrm{p}<0.001$ ) compared with the STR group, indicating that $\mathrm{MCH}$ alleviates depression-like behaviors (Fig. 4F, G). Similarly, the MCH (1 $\mu \mathrm{g} / 30$ $\mu \mathrm{l})$ and fluoxetine groups showed a significantly longer swimming time compared with the STR group ( $\mathrm{p}<0.05$, Fig. $4 \mathrm{H})$. However, a higher dose of $\mathrm{MCH}(25 \mu \mathrm{g} / 30 \mu \mathrm{l})$ did not result in improvements in depression-like behaviors (Fig. 4E H).

\section{Effects of MCH on serum corticosterone levels following stress}

Serum corticosterone was examined as an induction of hypothalamic-pituitary-adrenal (HPA) axis activity. Analysis of serum corticosterone levels revealed significant differences among the groups $\left[\mathrm{F}_{5,24}=40.94, \mathrm{p}<0.0001\right]$. Post hoc comparisons showed a significantly increased level of serum corticosterone in the STR group compared with that in the Nor group ( $p<0.001)$. In contrast, the $\mathrm{MCH} 1,5 \mu \mathrm{g} / 30 \mu \mathrm{l}$ groups showed a significant decrease in the concentration of corticosterone after fluoxetine compared with that in the STR group $(\mathrm{p}<0.001)$. These data suggest that $\mathrm{MCH}$ inhibits HPA axis hyperactivity in the STR (Fig. 4I).

\section{Effects of MCH on the mTOR signaling pathway in the PFC following stress}

To substantiate the molecular mechanisms underlying the antidepressant-like effects of MCH, we examined the phosphorylation of mTOR in the PFC of immobility-induced depressedlike mice. A one-way ANOVA revealed significant differences in $\mathrm{p}$-mTOR/mTOR $\left[\mathrm{F}_{5,23}=44.42, \mathrm{p}<0.0001\right]$. The phosphorylation level of mTOR was significantly decreased in the PFC of stressed mice $(\mathrm{p}<0.001)$ (Fig. 4J), which was restored by $\mathrm{MCH}(1 \mu \mathrm{g} / 30 \mu \mathrm{l})$ or fluoxetine treatment (MCH $1 \mu \mathrm{g}, \mathrm{p}<0.001$; fluoxetine, $\mathrm{p}<0.01$ ) (Fig. 4J). Next, the phosphorylation levels of synaptic proteins were examined. Western blotting confirmed that the phosphorylation levels of p-PSD95/PSD95 [ $\left.\mathrm{F}_{5,11}=57.70, \mathrm{p}<0.0001\right]$, p-GluR1/GluR1 
A
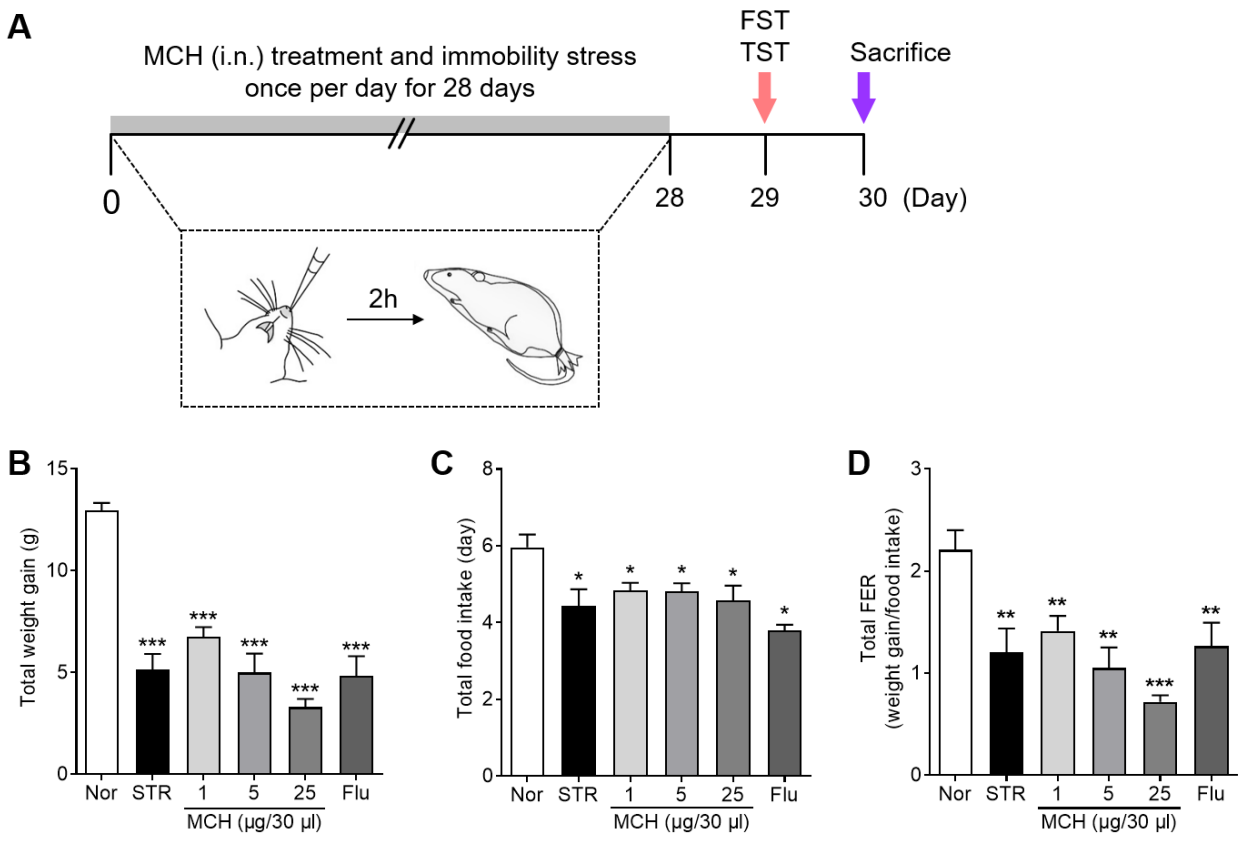

Tail suspension test
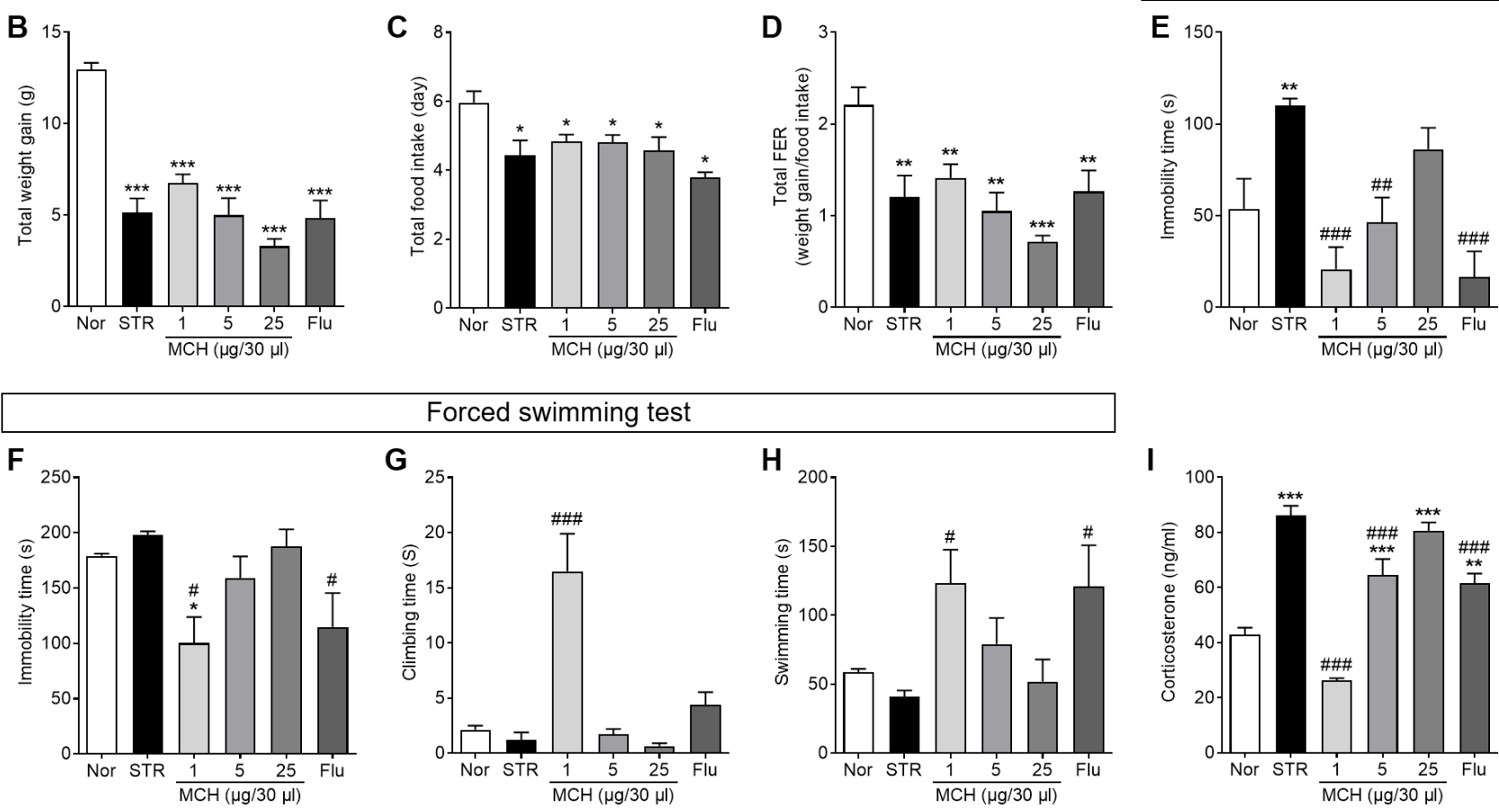

Forced swimming test
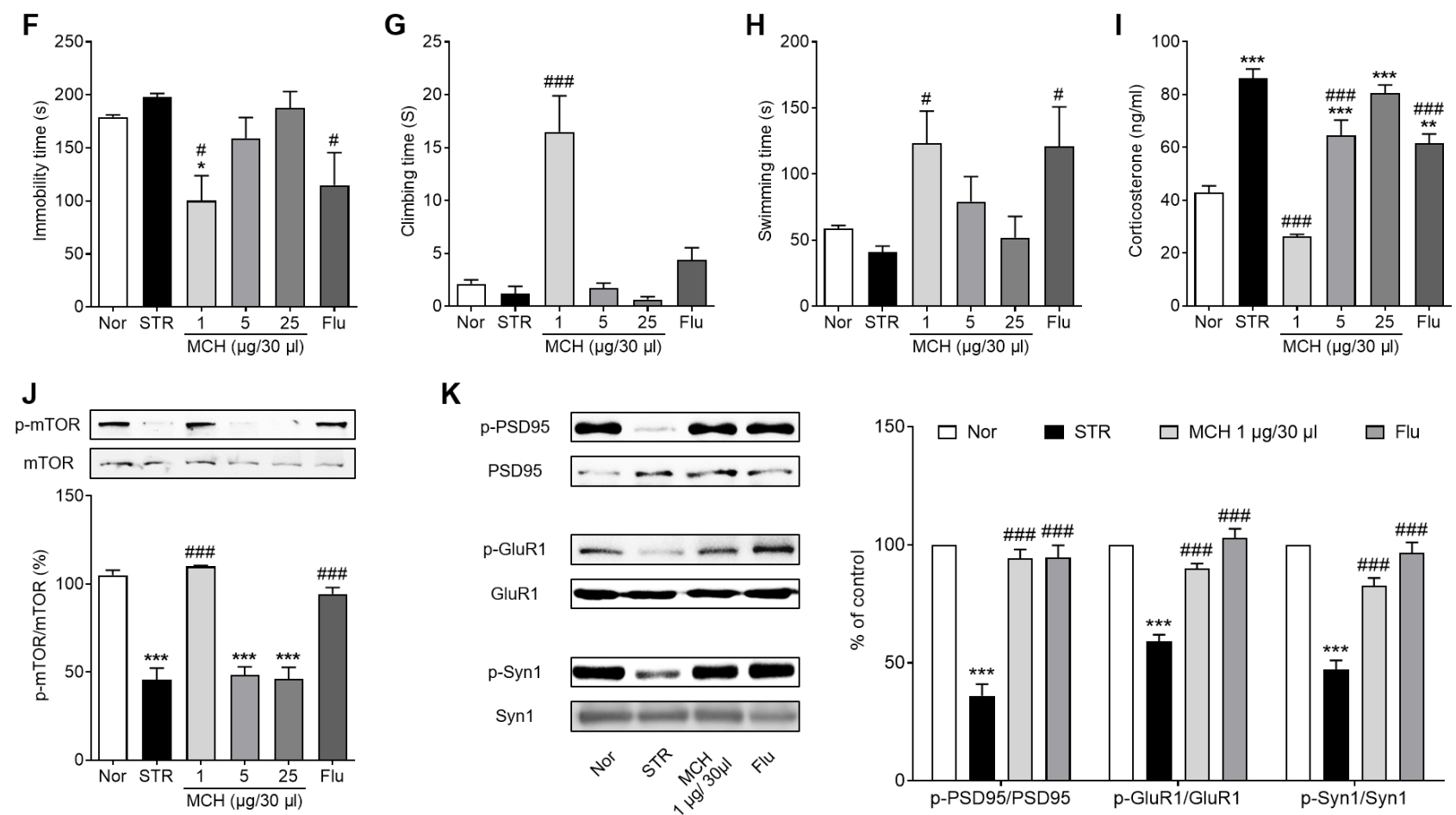

Fig. 4. Antidepressant-like effects of MCH in stressed mice. (A) Schematic representation of the STR paradigm. (B) Total weight gain was divided by (C) total food intake to calculate (D) total FER. (E) TST was administered during the 6-min test period and immobility time was recorded. (F) Immobility, (G) climbing, and (H) swimming behaviors in mice were observed during the last 4 min test period and climbing or swimming time was recorded. (I) Concentration of corticosterone was measured using an ELISA kit. The phosphorylation levels of (J) mTOR, (K) PSD95, GluR1 and Syn1 in the PFC were measured by immunoblotting. The amount of phosphorylated proteins were normalized to that of total proteins and presented as bar graphs (right panel). Data represent the means \pm SEM. ${ }^{* * *} \mathrm{p}<0.001,{ }^{* *} \mathrm{p}<0.01,{ }^{*} \mathrm{p}<0.05$ vs. Nor group, ${ }^{* * *} \mathrm{p}<0.001,{ }^{* *} \mathrm{p}<0.01,{ }^{*} \mathrm{p}<0.05$ vs. STR group. Nor, normal; STR, stress; Flu, fluoxetine; FST, forced swim test; TST, tail suspension test. 


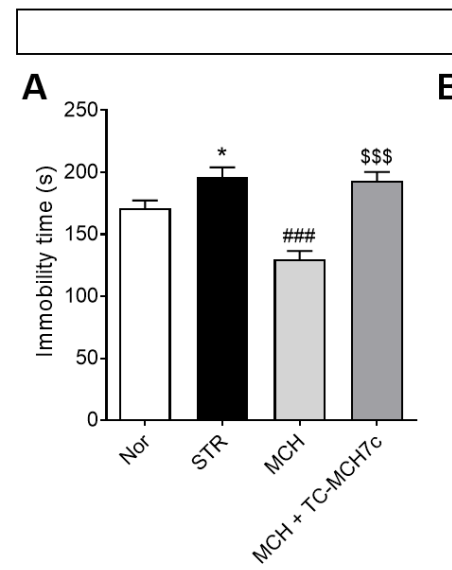

\section{Forced swimming test}

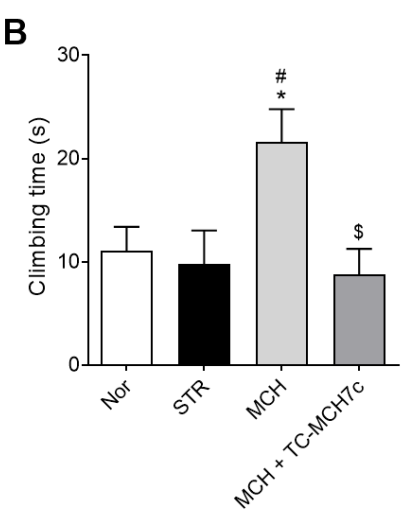

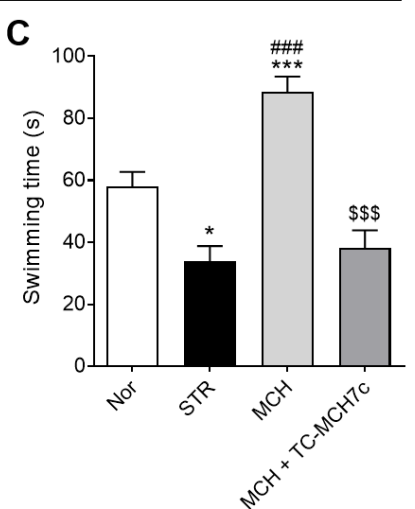

Tail suspension test

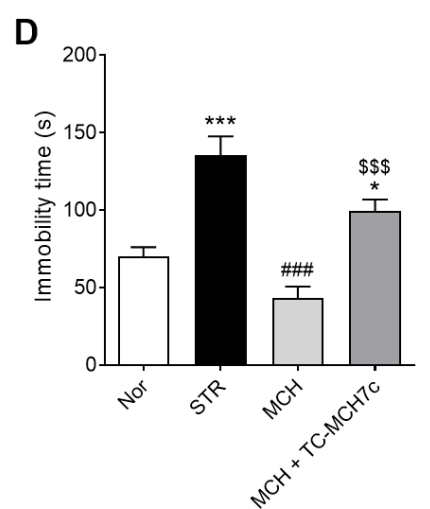

Fig. 5. Antidepressant-like effect of MCH is mediated by MCHR1. The FST was examined during the last 4 min of the test period and (A) immobility, (B) climbing, and (C) swimming behaviors were recorded in stressed mice. In the TST, (D) immobility behavior in mice were observed during the 6 min test period. $n=5$ /group. Data represent the means \pm SEM. ${ }^{* * *} \mathrm{p}<0.001,{ }^{*} \mathrm{p}<0.01$ vs. Nor group, ${ }^{\sharp \# *} \mathrm{p}<0.001,{ }^{\#} \mathrm{p}<0.05 \mathrm{vs}$. STR group $,{ }^{\$ S S} \mathrm{p}<0.001,{ }^{S} \mathrm{p}<0.05 \mathrm{Vs}$. MCH group. Nor, normal; STR, stress; $\mathrm{MCH}$, melanin-concentrating hormone.

$\left[\mathrm{F}_{5,11}=59.95, \mathrm{p}<0.0001\right]$, and $\mathrm{p}-\operatorname{Syn} 1 / \operatorname{Syn} 1\left[\mathrm{~F}_{5,11}=51.25, \mathrm{p}<0.0001\right]$ were significantly altered in the PFC between groups. Immobility stress reduced the phosphorylation levels $(\mathrm{p}<0.001)$, while $\mathrm{MCH}$ had a reverse effect $(\mathrm{p}<0.001)$ (Fig. $4 \mathrm{~K})$.

\section{Pretreatment with the MCH antagonist TC-MCH7c blocked the effect of $\mathrm{MCH}$}

To determine the involvement of MCHR1 in the regulation of depression-like behavior, we injected mice with TC-MCH7c, an $\mathrm{MCH}$ antagonist, at a dose of $10 \mathrm{mg} / \mathrm{kg}$, prior to an injection of $\mathrm{MCH}(1 \mu \mathrm{g} / 30 \mu \mathrm{l})$ and then proceeded to behavioral changes assessment. A one-way ANOVA of the FST data showed a significant difference in immobility $\left[\mathrm{F}_{3,19}=19.39, \mathrm{p}<0.0001\right]$, climbing $\left[\mathrm{F}_{3}\right.$, $\left.{ }_{19}=4.376, \mathrm{p}=0.0198\right]$, and swimming time $\left[\mathrm{F}_{3,19}=23.58, \mathrm{p}<0.0001\right]$. Post hoc analyses showed that the $\mathrm{MCH}+\mathrm{TC}-\mathrm{MCH} 7 \mathrm{c}$ group exhibited a pronounced depression-like phenotype (increased immobility) compared with the MCH group ( $<<0.001$, Fig. $5 \mathrm{~A}$ ). The $\mathrm{MCH}+\mathrm{TC}-\mathrm{MCH} 7 \mathrm{c}$ group exhibited a decrease in climbing time compared with the $\mathrm{MCH}$ group ( $\mathrm{p}<0.05$, Fig. $5 \mathrm{~B}$ ). In addition, the $\mathrm{MCH}+\mathrm{TC}-\mathrm{MCH} 7 \mathrm{c}$ group showed a significant decrease in swimming time ( $\mathrm{p}<0.001$, Fig. $5 \mathrm{C})$. Next, we performed a TST $\left[\mathrm{F}_{3,19}=21.46, \mathrm{p}<0.0001\right]$, with the $\mathrm{MCH}$ group showing decreased immobility time compared with the STR group ( $<<0.001)$, but not the $\mathrm{MCH}+\mathrm{TC}-\mathrm{MCH} 7$ c group (Fig. 5D).

\section{Dual effects of MCH according to the administration path- way}

Our results show that $\mathrm{MCH}$ intranasal administration improves stress-induced depression- and anxiety-like effects by regulating the mTOR signaling pathway and synaptic plasticity (Fig. 6A). However, in previous studies, microinjection of $\mathrm{MCH}$ has been shown to cause depression (Fig. 6B). Therefore, we analyzed TST after administering $\mathrm{MCH}$ in two different ways in naïve unstressed mice. As a result, depression-like behavior was not observed after intranasal administration of $\mathrm{MCH}$ at $0,1,10$, or $20 \mu \mathrm{g}$ (Fig. 6C), but was observed following a microinjection into the DRN at 0,50, or $100 \mathrm{ng}$ (Fig. 6D). Therefore, $\mathrm{MCH}$ has a dual effect depending on the route of administration.

\section{Distribution in the brain region after intranasal adminis- tration of $M C H$}

We administered MCH-FITC to assess the extent of brain infiltration. Starting from the olfactory bulb (Fig. 7A), $\mathrm{MCH}$ was detected in depression-related regions, including the PFC (Fig. 7B), thalamus (Fig. 7C), hippocampus (Fig. 7D), and amygdala (Fig. $7 \mathrm{E})$.

\section{DISCUSSION}

In this study, we investigated the antidepressant-like effects of $\mathrm{MCH}$ using stress models in rats and mice (Figs. 1, 4). We found that these effects were mediated by the activation of mTOR signaling molecules (Fig. 2) and were inhibited by an mTOR inhibitor (Fig. 3) and MCHR1 antagonist (Fig. 5). As far as we know, this is the first study to show the therapeutic potential of $\mathrm{MCH}$ in the stress-induced depression model.

In our study of stressed rats, we showed that $\mathrm{MCH}$ exhibited antidepressant-like effects at all 2, 8, and $18 \mu \mathrm{g} / 30 \mu \mathrm{l}$ doses (Fig. 1). 
A

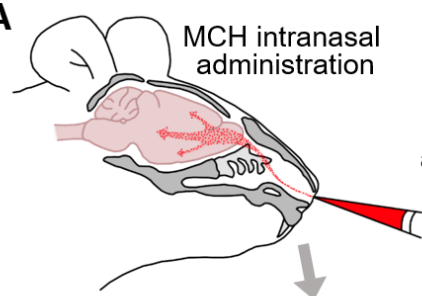

Antidepressive and anxiolytic-like effects of $\mathrm{MCH}$

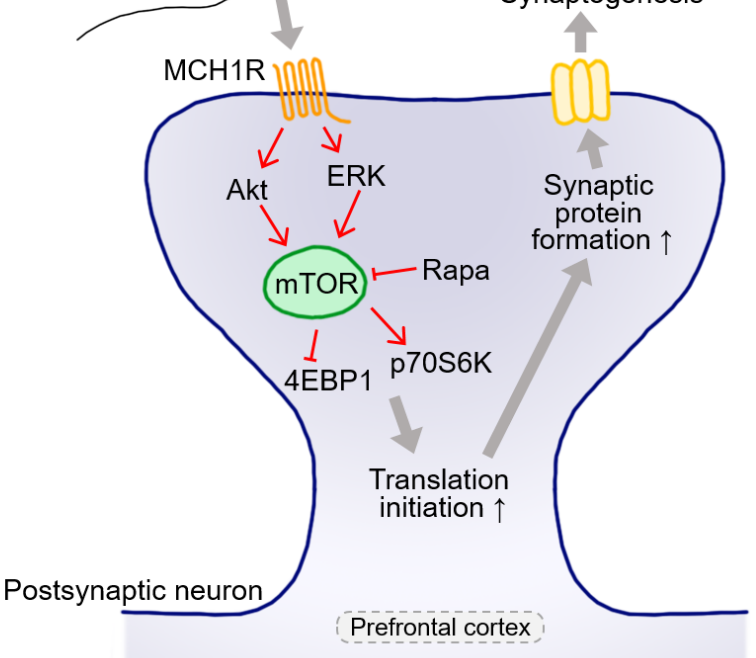

C

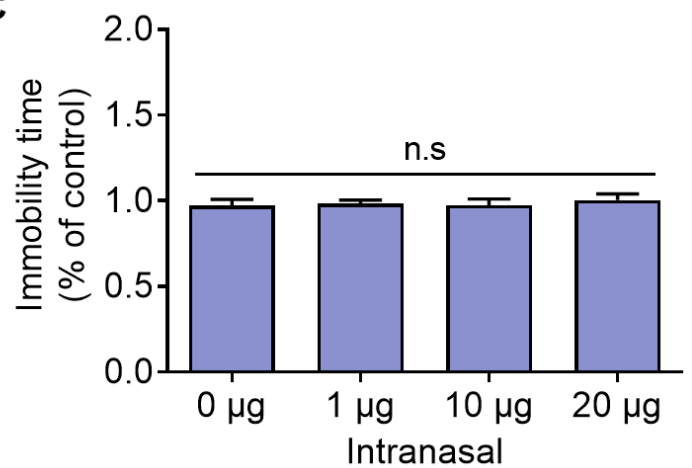

B

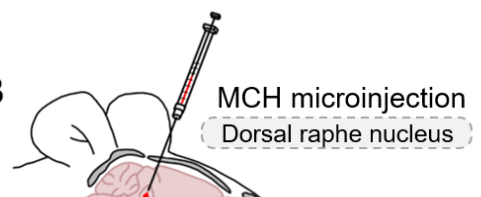

Inhibition of serotonergic neuron Dorsal raphe nucleus

(Devera et al., 2015)

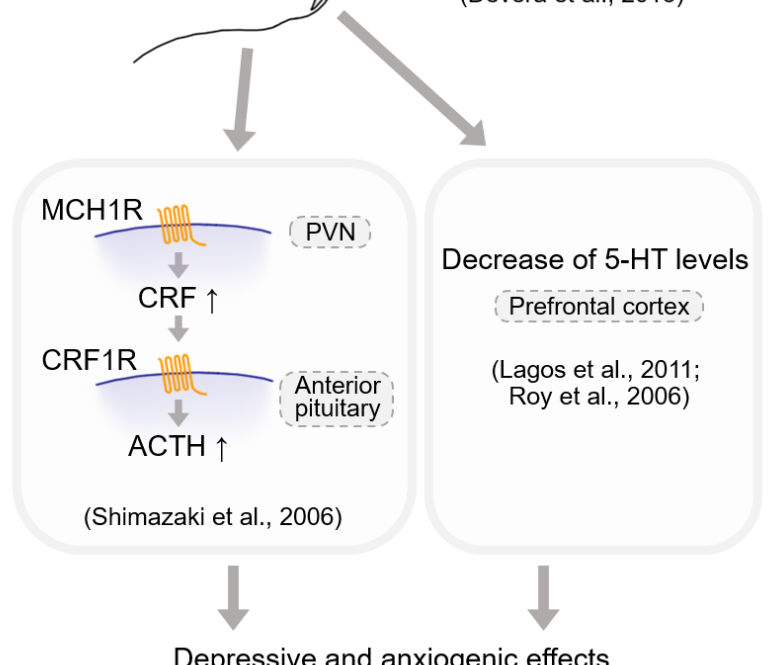

Depressive and anxiogenic effects

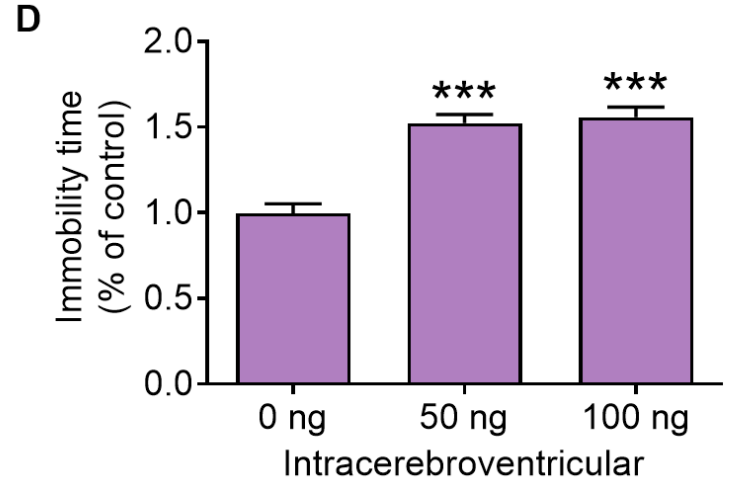

Fig. 6. The effect of MCH on depression- or anxiety-like behaviors is based on the route of administration. (A) In this study, intranasal administration of $\mathrm{MCH}$ produced antidepressant- and anxiolytic-like behaviors in both rodent models. MCH treatment intranasally increases the activation of Akt and ERK, and these induced the phosphorylation of mTOR. Phosphorylation of mTOR hyperphosphorylates 4EBP1 and p70S6K, thus promoting an increase in synaptic formation in the PFC. However, pretreatment with the mTOR inhibitor, rapamycin prevented these changes. (B) In contrast, a microinjection of $\mathrm{MCH}$ into the DRN induced depression- and anxiogenic-like behaviors. Previous studies have suggested that a microinjection of $\mathrm{MCH}$ induces depression-like and anxiogenic effects possibly via the inhibition of serotonergic neurons in the DRN, increasing the secretion of CRF, which promotes the release of ACTH from the anterior pituitary, and a decrease in 5-HT levels in the PFC. (C) Intranasal administration of MCH produced no changes in immobility time in the TST, whereas (D) microinjection of MCH into the DRN induced depression-like behaviors in the TST. Data represent the means \pm SEM. ${ }^{* *} \mathrm{p}<0.001$ vs. $0 \mu$ g or 0 ng.

However, in our study of stressed mice, only a low dose of $\mathrm{MCH}(1$ $\mu \mathrm{g} / 30 \mu \mathrm{l})$ elicited antidepressant-like effects, whereas a high dose of $\mathrm{MCH}(25 \mu \mathrm{g} / 30 \mu \mathrm{l})$ did not (Fig. 4). When the doses were normalized by body weight, each dose was equivalent to 10,40 , and 90 $\mu \mathrm{g} / \mathrm{kg}$ in rats and 50,250, and $1,250 \mu \mathrm{g} / \mathrm{kg}$ in mice. In addition, the mice received twice the dose $(20,80$, and $180 \mu \mathrm{g} / \mathrm{kg})$ administered to rats, when scaled to rat size by surface area [29]. These results suggest that efficacious doses of $\mathrm{MCH}$ are actually similar between rats and mice.

In the present study, we demonstrated that stress reduced the 
A Olfactory bulb

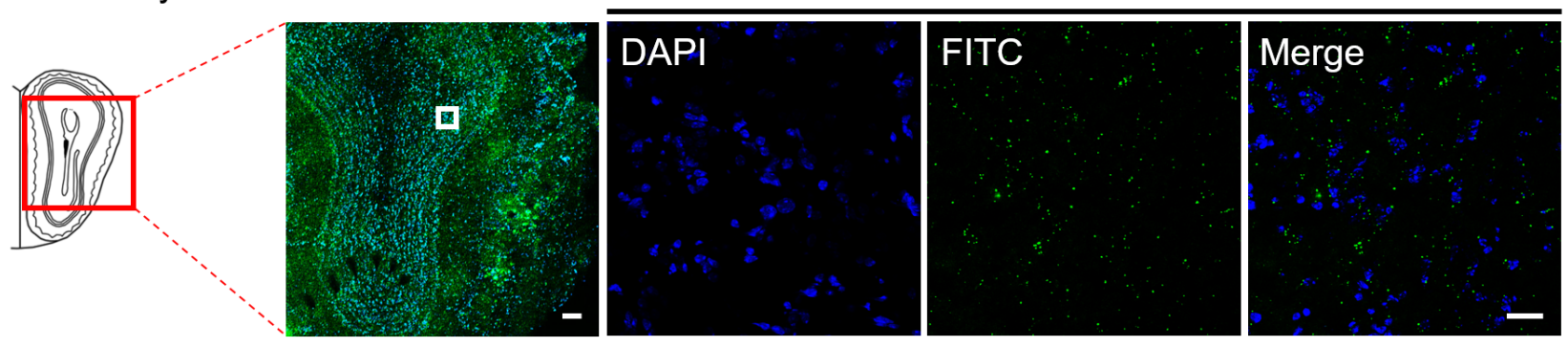

B Prefrontal cortex
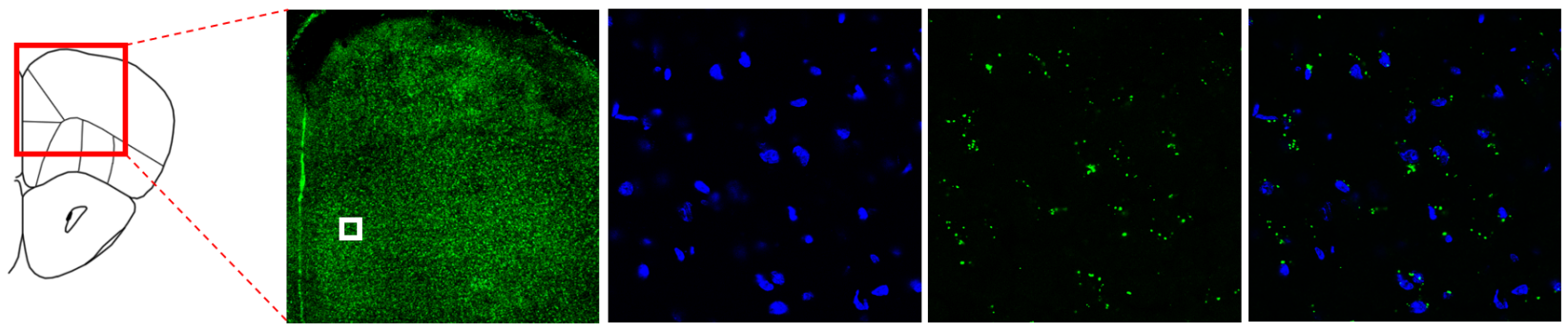

C Thalamus
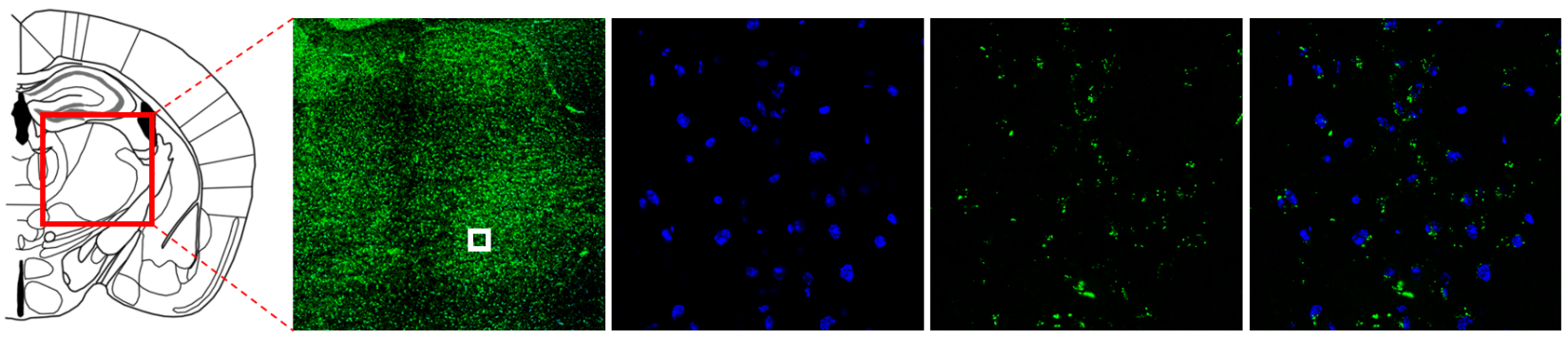

D Hippocampus
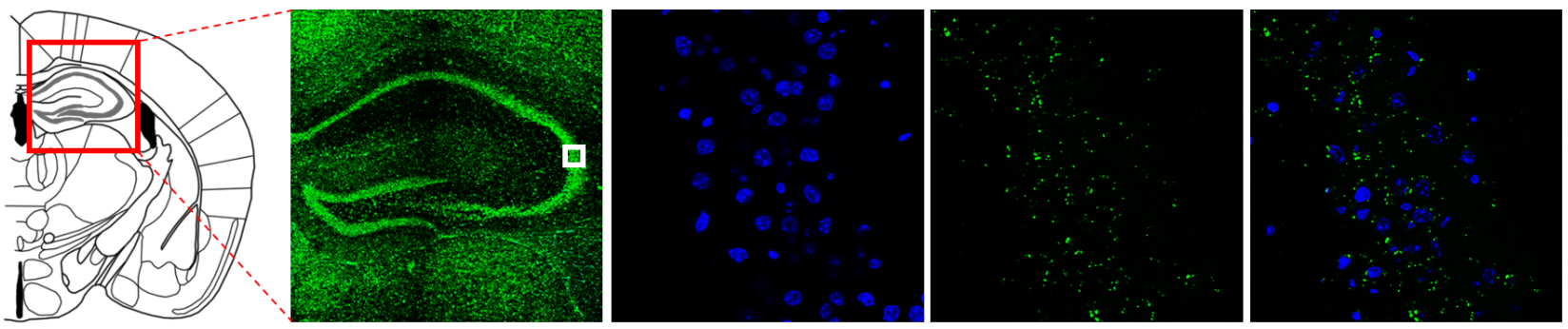

\section{E Amygdala}
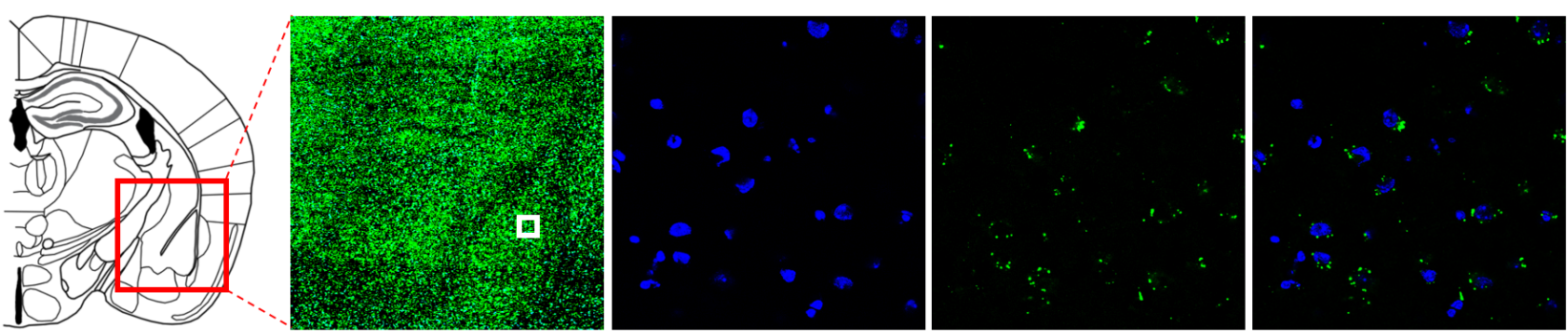

Fig. 7. Distribution of $\mathrm{MCH}$ in the brain after intranasal administration. Representative figure showing the distribution of $\mathrm{MCH}$ after $30 \mathrm{~min}$ of intranasal administration of MCH-FITC (10 $\mu \mathrm{g} / 30 \mu \mathrm{l})$ in the (A) olfactory bulb, (B) PFC, (C) thalamus, (D) hippocampus, and (E) amygdala of mouse brain. Scale bar: 400 and $30 \mu \mathrm{m}$. 
phosphorylation of mTOR, Akt, and ERK in the PFC, whereas $\mathrm{MCH}$ reversed this stress-induced dephosphorylation (Fig. 6A). Activation of the mTOR signaling pathway is associated with many physiological processes of the nervous system, including neurogenesis, axonal sprouting, dendritic spine growth, and psychiatric disorders such as MDD [28, 30]. The upstream activators of mTOR signaling are Akt and ERK, which can inhibit tuberous sclerosis complexes (TSC1 and TSC2), known inhibitors of mTOR [31]. MCH interacts with its receptor MCHR1 which leads to activation of the intracellular signaling pathway. MCHR1 signaling increases intracellular calcium mobilization via G-coupled pathways and activates ERK phosphorylation in recombinant cell lines and hippocampal brain slices $[32,33]$. Moreover, $\mathrm{MCH}$-induced neurite outgrowth is required for ERK activation in SH-SY5Y cells [34], suggesting that $\mathrm{MCH}$-induced ERK activation may be involved in mTOR phosphorylation in the brain. The downstream targets of mTOR are ribosomal protein S6 kinases (S6Ks) and eukaryotic initiation factor $4 \mathrm{E}$ (eIF4E)-binding proteins (4E-BP), which regulate protein biosynthesis [31]. We also showed that $\mathrm{MCH}$ reverses S6K activation in the PFC in stressed rats (Fig. 3). Previous studies using animal models of depression have reported decreased mTOR activity and reductions in the phosphatidylinositol 3-kinase (PI3K)/Akt/mTOR signaling pathway in the PFC, hippocampus, and amygdala of stressed rats $[28,30]$. Congruent with PFC, the hippocampal mTOR protein levels in STR was significantly decreased compared to NOR, while it was restored after intranasal administration of $18 \mu \mathrm{g} / 30 \mu \mathrm{MCH}$ (data not shown). In addition, our previous study found that $\mathrm{MCH}$ increased hippocampal LTP [35]. These results suggest that MCH exerts its antidepressantlike effect through activation of the Akt/mTOR/S6K signaling pathway. Additionally, to produce the antidepressant-like effects of $\mathrm{MCH}$, other brain regions, such as the hippocampus, contribute to the activity of these pathways $[36,37]$.

The ability of synapses to undergo dynamic rearrangement is important for brain function, and the number or function of synapses can be altered by stress [38, 39]. Among synaptic proteins, Syn 1 and PSD95 play important roles in synaptic plasticity [40, 41] and synapse maturation [40]. Syn 1 is widely distributed in presynaptic vesicle membranes, and PSD95 is the main protein in excitatory postsynaptic density material. Both of these proteins are activated by phosphorylation of the serine residues for synaptic function, Ser-295 of PSD95 [42], and Ser-603 of Syn1 [43]. In the present study, Syn 1 and PSD95 expression was induced by $\mathrm{MCH}$ treatment, suggesting that $\mathrm{MCH}$ may increase synaptic strength through the activation of these proteins. Moreover, GluR1 is regulated by phosphorylation and dephosphorylation. The phosphorylation of Ser-845 of GluR1 enhances native and recombinant
AMPA receptor currents [42, 44], whereas dephosphorylation induces long-term depression [45]. Furthermore, MCHR1 activation increases intracellular calcium mobilization via G-coupled pathways [32], and postsynaptic $\mathrm{Ca}^{2+}$ influx is critical for LTP induction [46]. Consistent with these findings, our data suggest stress induced dephosphorylation of Syn1, PDS95, and GluR1 in the PFC, whereas MCH restored the phosphorylation of these proteins (Figs. 2, 4).

Several studies have related $\mathrm{MCH}$ to depression, although not consistently $[8,47]$. For example, MCH has been shown to evoke depression-like behavior after a microinjection into the DRN [47] or locus coeruleus [48] in the brainstem, as demonstrated by a significant increase in immobility time in the FST, a decrease in climbing behavior, or a decrease in sucrose preference [47, 48]. In fact, when $50 \mathrm{ng}$ of $\mathrm{MCH}$ is administered into the DRN, rats display depression-like behavior [49]. In contrast, an injection of a lower dose of $\mathrm{MCH}(25 \mathrm{ng})$ has been shown to produce a significant decrease in immobility time [49]. Moreover, a microinjection of $\mathrm{MCH}$ is sufficient to induce depression-like behavior $30 \mathrm{~min}$ after the injection, but the effect is lost after $60 \mathrm{~min}$. These findings suggest that the effect of $\mathrm{MCH}$ on depression-like behaviors is transient and varies depending on its dose. Several studies have produced results that contrast with our findings, particularly those involving MCHR antagonists or transgenic mice. Borowsky et al. [50] first suggested that the small-molecule MCHR1 antagonist SNAP-7941 may be useful in the management of obesity and for the treatment of depression and anxiety. MCHR1 antagonists reverse depression-like behavior in both acute and chronic models of depression [51-53]. The genetic inactivation of MCHR1 in female mice also produces antidepressant-like effects in the FST [54]. However, genetic deletion of MCHR1 in male mice does not produce an antidepressant-like effect [54], and some MCHR1 antagonists have failed to show antidepressant-like effects in other models [55], adding to the uncertainty regarding the roles of $\mathrm{MCH}$ in depression-related behaviors.

One possible explanation for these discrepancies is the differences among sites of action. As reported in this study, intranasal delivery of $\mathrm{MCH}$ allows for distribution to various brain regions within 30 min, including the olfactory bulb, PFC, thalamus, hippocampus, and amygdala (Fig. 7). Although intranasally administered $\mathrm{MCH}$ diffuses to reach various brain regions [23], the anterior or middle parts of the brain, including the PFC and hippocampus, are more likely to play important roles in inducing therapeutic effects. Our recent findings also support this hypothesis. Intranasal administration of MCH improved pain-induced depression-like behaviors as well as pain, and these effects were correlated with the expression of cannabinoid receptor 1 in the PFC [23]. Intranasal MCH has 
also been shown to attenuate cognitive impairment in Alzheimer's disease models; these effects are mediated by enhancing longterm potentiation and increasing levels of phosphorylated CREB and GSK3 $\beta$ in the hippocampus [56]. In contrast, previous studies have mainly focused on regions of the hindbrain, such as the raphe nucleus [47] or locus coeruleus [48]. To verify the occurrence of region-specific effects of $\mathrm{MCH}$, we compared the immobility time of two differentially administered MCH groups using the TST, and found that the intranasal group did not display an increase in immobility time, whereas the DRN microinjection group did (Fig. 6C, D). Our speculations about the differential effects and mechanisms of these $\mathrm{MCH}$ administration pathways are shown in Fig. $6 \mathrm{~A}, \mathrm{~B}$.

We administered MCH intranasally, which allows for rapid entry of peptides into the brain, bypassing the blood-brain barrier [57]. Distributed to various brain regions within $30 \mathrm{~min}$, including the olfactory bulb, PFC, thalamus, hippocampus, and amygdala (Fig. 7), intranasally administered MCH may exert its antidepressantlike effect more promptly. Recently, intranasal administration of $\mathrm{MCH}$ has been shown to have neuroprotective effects through the enhancement of neuronal synapses and long-term potentiation (LTP) in the hippocampus of 5XFAD AD mice [56]. However, future studies are needed to elucidate the differential expression of MCH-FITC in rats and mice.

$\mathrm{MCH}$ overexpression may enhance food intake, reduce glucose tolerance, and provoke insulin resistance, resulting in obesity in mice [21]. However, we did not observe weight gain or a FER difference between the control and $\mathrm{MCH}$-treated groups, suggesting that $\mathrm{MCH}$ has no adverse effects on energy homeostasis after intranasal administration of the doses used in this study, even when compared with fluoxetine at the same doses.

In conclusion, we demonstrated that the antidepressant-like effects of intranasally administered $\mathrm{MCH}$ in stressed rats and mice is mediated via the mTOR signaling pathway. Our findings provide novel insight into the molecular mechanism(s) underlying the protective effects of $\mathrm{MCH}$ in depression and promote $\mathrm{MCH}$ as a potential therapeutic agent for depression.

\section{ACKNOWLEDGEMENTS}

This research was supported by grants from the National Research Foundation of Korea funded by the Korean government (NRF-2015M3A9E3052338 and 2017R1A2B4009963), the Korea Institute of Oriental Medicine (grant K18182), and the Korean Health Technology R\&D Project funded by the Ministry of Health and Welfare (HI16C0405, HI18C1077) of the Republic of Korea.

\section{REFERENCES}

1. American Psychiatric Association (2013) Diagnostic and statistical manual of mental disorders: DSM-5.5th ed. American Psychiatric Association, Arlington.

2. World Health Organization (2008) The global burden of disease: 2004 update. World Health Organization, Geneva.

3. Young EA, Kotun J, Haskett RF, Grunhaus L, Greden JF, Watson SJ, Akil H (1993) Dissociation between pituitary and adrenal suppression to dexamethasone in depression. Arch Gen Psychiatry 50:395-403.

4. Kalia M (2005) Neurobiological basis of depression: an update. Metabolism 54(5 Suppl 1):24-27.

5. Berton O, Nestler EJ (2006) New approaches to antidepressant drug discovery: beyond monoamines. Nat Rev Neurosci 7:137-151.

6. Monti JM (2010) The role of dorsal raphe nucleus serotonergic and non-serotonergic neurons, and of their receptors, in regulating waking and rapid eye movement (REM) sleep. Sleep Med Rev 14:319-327.

7. Olivier B (2015) Serotonin: a never-ending story. Eur J Pharmacol 753:2-18.

8. Torterolo P, Scorza C, Lagos P, Urbanavicius J, Benedetto L, Pascovich C, López-Hill X, Chase MH, Monti JM (2015) Melanin-concentrating hormone $(\mathrm{MCH})$ : role in REM sleep and depression. Front Neurosci 9:475.

9. Kawauchi H, Kawazoe I, Tsubokawa M, Kishida M, Baker BI (1983) Characterization of melanin-concentrating hormone in chum salmon pituitaries. Nature 305:321-323.

10. Nahon JL, Presse F, Bittencourt JC, Sawchenko PE, Vale W (1989) The rat melanin-concentrating hormone messenger ribonucleic acid encodes multiple putative neuropeptides coexpressed in the dorsolateral hypothalamus. Endocrinology 125:2056-2065.

11. Presse F, Nahon JL, Fischer WH, Vale W (1990) Structure of the human melanin concentrating hormone mRNA. Mol Endocrinol 4:632-637.

12. Qu D, Ludwig DS, Gammeltoft S, Piper M, Pelleymounter MA, Cullen MJ, Mathes WF, Przypek R, Kanarek R, MaratosFlier E (1996) A role for melanin-concentrating hormone in the central regulation of feeding behaviour. Nature 380:243247.

13. Bittencourt JC, Presse F, Arias C, Peto C, Vaughan J, Nahon JL, Vale W, Sawchenko PE (1992) The melanin-concentrating hormone system of the rat brain: an immuno- and hybridization histochemical characterization. J Comp Neurol 319:218245. 
14. Saito Y, Cheng M, Leslie FM, Civelli O (2001) Expression of the melanin-concentrating hormone $(\mathrm{MCH})$ receptor mRNA in the rat brain. J Comp Neurol 435:26-40.

15. Mashiko S, Ishihara A, Gomori A, Moriya R, Ito M, Iwaasa H, Matsuda M, Feng Y, Shen Z, Marsh DJ, Bednarek MA, MacNeil DJ, Kanatani A (2005) Antiobesity effect of a melaninconcentrating hormone 1 receptor antagonist in diet-induced obese mice. Endocrinology 146:3080-3086.

16. Bencze J, Pocsai K, Murnyák B, Gergely PA, Juhász B, Szilvássy Z, Hortobágyi T (2018) The Melanin-concentrating hormone system in human, rodent and avian brain. Open Med (Wars) 13:264-269.

17. Unmehopa UA, van Heerikhuize JJ, Spijkstra W, Woods JW, Howard AD, Zycband E, Feighner SD, Hreniuk DL, Palyha OC, Guan XM, Macneil DJ, Van der Ploeg LH, Swaab DF (2005) Increased melanin concentrating hormone receptor type I in the human hypothalamic infundibular nucleus in cachexia. J Clin Endocrinol Metab 90:2412-2419.

18. Ahnaou A, Drinkenburg WH, Bouwknecht JA, Alcazar J, Steckler T, Dautzenberg FM (2008) Blocking melanin-concentrating hormone $\mathrm{MCH} 1$ receptor affects rat sleep-wake architecture. Eur J Pharmacol 579:177-188.

19. Benedetto L, Rodriguez-Servetti Z, Lagos P, D'Almeida V, Monti JM, Torterolo P (2013) Microinjection of melanin concentrating hormone into the lateral preoptic area promotes non-REM sleep in the rat. Peptides 39:11-15.

20. Adams AC, Domouzoglou EM, Chee MJ, Segal-Lieberman G, Pissios P, Maratos-Flier E (2011) Ablation of the hypothalamic neuropeptide melanin concentrating hormone is associated with behavioral abnormalities that reflect impaired olfactory integration. Behav Brain Res 224:195-200.

21. Macneil DJ (2013) The role of melanin-concentrating hormone and its receptors in energy homeostasis. Front Endocrinol (Lausanne) 4:49.

22. Belzung C (2014) Innovative drugs to treat depression: did animal models fail to be predictive or did clinical trials fail to detect effects? Neuropsychopharmacology 39:1041-1051.

23. Jang JH, Park JY, Oh JY, Bae SJ, Jang H, Jeon S, Kim J, Park HJ (2018) Novel analgesic effects of melanin-concentrating hormone on persistent neuropathic and inflammatory pain in mice. Sci Rep 8:707.

24. Serova LI, Laukova M, Alaluf LG, Sabban EL (2013) Intranasal infusion of melanocortin receptor four (MC4R) antagonist to rats ameliorates development of depression and anxiety related symptoms induced by single prolonged stress. Behav Brain Res 250:139-147.

25. Koprdova R, Bögi E, Belovičová K, Sedláčková N, Okuliarová
M, Ujházy E, Mach M (2016) Chronic unpredictable mild stress paradigm in male Wistar rats: effect on anxiety- and depressive-like behavior. Neuro Endocrinol Lett 37(Suppl1):103-110.

26. Shin MS, Park SS, Lee JM, Kim TW, Kim YP (2017) Treadmill exercise improves depression-like symptoms by enhancing serotonergic function through upregulation of 5-HT1A expression in the olfactory bulbectomized rats. J Exerc Rehabil 13:36-42.

27. Ignácio ZM, Réus GZ, Arent CO, Abelaira HM, Pitcher MR, Quevedo J (2016) New perspectives on the involvement of mTOR in depression as well as in the action of antidepressant drugs. Br J Clin Pharmacol 82:1280-1290.

28. Abelaira HM, Réus GZ, Neotti MV, Quevedo J (2014) The role of mTOR in depression and antidepressant responses. Life Sci 101:10-14.

29. Reagan-Shaw S, Nihal M, Ahmad N (2008) Dose translation from animal to human studies revisited. FASEB J 22:659-661.

30. Laplante M, Sabatini DM (2012) mTOR signaling in growth control and disease. Cell 149:274-293.

31. Takei N, Nawa H (2014) mTOR signaling and its roles in normal and abnormal brain development. Front Mol Neurosci $7: 28$.

32. Hawes BE, Kil E, Green B, O'Neill K, Fried S, Graziano MP (2000) The melanin-concentrating hormone receptor couples to multiple $\mathrm{G}$ proteins to activate diverse intracellular signaling pathways. Endocrinology 141:4524-4532.

33. Pissios P, Trombly DJ, Tzameli I, Maratos-Flier E (2003) Melanin-concentrating hormone receptor 1 activates extracellular signal-regulated kinase and synergizes with $G(\mathrm{~s})$-coupled pathways. Endocrinology 144:3514-3523.

34. Cotta-Grand N, Rovère C, Guyon A, Cervantes A, Brau F, Nahon JL (2009) Melanin-concentrating hormone induces neurite outgrowth in human neuroblastoma SH-SY5Y cells through $\mathrm{p} 53$ and MAPKinase signaling pathways. Peptides 30:2014-2024.

35. Oh ST, Liu QF, Jeong HJ, Lee S, Samidurai M, Jo J, Pak SC, Park HJ, Kim J, Jeon S (2019) Nasal cavity administration of melanin-concentrating hormone improves memory impairment in memory-impaired and Alzheimer's disease mouse models. Mol Neurobiol 56:8076-8086.

36. Frodl T, Jäger M, Smajstrlova I, Born C, Bottlender R, Palladino T, Reiser M, Möller HJ, Meisenzahl EM (2008) Effect of hippocampal and amygdala volumes on clinical outcomes in major depression: a 3-year prospective magnetic resonance imaging study. J Psychiatry Neurosci 33:423-430.

37. Varas M, Pérez M, Monzón ME, de Barioglio SR (2002) Mela- 
nin-concentrating hormone, hippocampal nitric oxide levels and memory retention. Peptides 23:2213-2221.

38. Pittenger C, Duman RS (2008) Stress, depression, and neuroplasticity: a convergence of mechanisms. Neuropsychopharmacology 33:88-109.

39. Krishnan V, Nestler EJ (2010) Linking molecules to mood: new insight into the biology of depression. Am J Psychiatry 167:1305-1320.

40. El-Husseini AE, Schnell E, Chetkovich DM, Nicoll RA, Bredt DS (2000) PSD-95 involvement in maturation of excitatory synapses. Science 290:1364-1368.

41. Cesca F, Baldelli P, Valtorta F, Benfenati F (2010) The synapsins: key actors of synapse function and plasticity. Prog Neurobiol 91:313-348.

42. Roche KW, O'Brien RJ, Mammen AL, Bernhardt J, Huganir RL (1996) Characterization of multiple phosphorylation sites on the AMPA receptor GluR1 subunit. Neuron 16:1179-1188.

43. Sakurada K, Kato H, Nagumo H, Hiraoka H, Furuya K, Ikuhara T, Yamakita Y, Fukunaga K, Miyamoto E, Matsumura F, Matsuo YI, Naito Y, Sasaki Y (2002) Synapsin I is phosphorylated at Ser603 by p21-activated kinases (PAKs) in vitro and in PC12 cells stimulated with bradykinin. J Biol Chem 277:45473-45479.

44. Banke TG, Bowie D, Lee H, Huganir RL, Schousboe A, Traynelis SF (2000) Control of GluR1 AMPA receptor function by cAMP-dependent protein kinase. J Neurosci 20:89102.

45. Kameyama K, Lee HK, Bear MF, Huganir RL (1998) Involvement of a postsynaptic protein kinase A substrate in the expression of homosynaptic long-term depression. Neuron 21:1163-1175.

46. Raymond CR (2007) LTP forms 1, 2 and 3: different mechanisms for the "long" in long-term potentiation. Trends Neurosci 30:167-175.

47. Lagos P, Urbanavicius J, Scorza MC, Miraballes R, Torterolo P (2011) Depressive-like profile induced by MCH microinjections into the dorsal raphe nucleus evaluated in the forced swim test. Behav Brain Res 218:259-266.

48. Ye H, Cui XY, Ding H, Cui SY, Hu X, Liu YT, Zhao HL, Zhang YH (2018) Melanin-concentrating hormone (MCH) and $\mathrm{MCH}-\mathrm{R} 1$ in the Locus coeruleus may be involved in the regulation of depressive-like behavior. Int J Neuropsychopharmacol 21:1128-1137.

49. Urbanavicius J, Lagos P, Torterolo P, Scorza C (2014) Prodepressive effect induced by microinjections of $\mathrm{MCH}$ into the dorsal raphe: time course, dose dependence, effects on anxi- ety-related behaviors, and reversion by nortriptyline. Behav Pharmacol 25:316-324.

50. Borowsky B, Durkin MM, Ogozalek K, Marzabadi MR, DeLeon J, Lagu B, Heurich R, Lichtblau H, Shaposhnik Z, Daniewska I, Blackburn TP, Branchek TA, Gerald C, Vaysse PJ, Forray C (2002) Antidepressant, anxiolytic and anorectic effects of a melanin-concentrating hormone-1 receptor antagonist. Nat Med 8:825-830.

51. Chaki S, Funakoshi T, Hirota-Okuno S, Nishiguchi M, Shimazaki T, Iijima M, Grottick AJ, Kanuma K, Omodera K, Sekiguchi Y, Okuyama S, Tran TA, Semple G, Thomsen W (2005) Anxiolytic- and antidepressant-like profile of ATC0065 and ATC0175: nonpeptidic and orally active melanin-concentrating hormone receptor 1 antagonists. J Pharmacol Exp Ther 313:831-839.

52. Smith DG, Hegde LG, Wolinsky TD, Miller S, Papp M, Ping X, Edwards T, Gerald CP, Craig DA (2009) The effects of stressful stimuli and hypothalamic-pituitary-adrenal axis activation are reversed by the melanin-concentrating hormone 1 receptor antagonist SNAP 94847 in rodents. Behav Brain Res 197:284-291.

53. Gehlert DR, Rasmussen K, Shaw J, Li X, Ardayfio P, Craft L, Coskun T, Zhang HY, Chen Y, Witkin JM (2009) Preclinical evaluation of melanin-concentrating hormone receptor 1 antagonism for the treatment of obesity and depression. J Pharmacol Exp Ther 329:429-438.

54. Roy M, David N, Cueva M, Giorgetti M (2007) A study of the involvement of melanin-concentrating hormone receptor 1 (MCHR1) in murine models of depression. Biol Psychiatry 61:174-180.

55. Basso AM, Bratcher NA, Gallagher KB, Cowart MD, Zhao C, Sun M, Esbenshade TA, Brune ME, Fox GB, Schmidt M, Collins CA, Souers AJ, Iyengar R, Vasudevan A, Kym PR, Hancock AA, Rueter LE (2006) Lack of efficacy of melaninconcentrating hormone-1 receptor antagonists in models of depression and anxiety. Eur J Pharmacol 540:115-120.

56. Oh ST, Liu QF, Jeong HJ, Lee S, Samidurai M, Jo J, Pak SC, Park HJ, Kim J, Jeon S (2019) Nasal cavity administration of melanin-concentrating hormone improves memory impairment in memory-impaired and Alzheimer's disease mouse models. Mol Neurobiol 56:8076-8086.

57. Thorne RG, Pronk GJ, Padmanabhan V, Frey WH 2nd (2004) Delivery of insulin-like growth factor-I to the rat brain and spinal cord along olfactory and trigeminal pathways following intranasal administration. Neuroscience 127:481-496. 